\title{
Review on thermochromic vanadium dioxide based smart coatings: from lab to commercial application
}

\author{
Tian-Ci Chang ${ }^{1,2,3} \cdot$ Xun Cao $^{1,2}$ (1) Shan-Hu Bao ${ }^{1,2} \cdot$ Shi-Dong $\mathrm{Ji}^{1,2} \cdot$ \\ Hong-Jie Luo ${ }^{4} \cdot$ Ping Jin ${ }^{1,2,5}$
}

Received: 16 December 2017/ Accepted: 29 December 2017/Published online: 24 January 2018

(C) The Author(s) 2018. This article is an open access publication

\begin{abstract}
With an urgent demand of energy efficient coatings for building fenestrations, vanadium dioxide $\left(\mathrm{VO}_{2}\right)$-based thermochromic smart coatings have been widely investigated due to the reversible phase transition of $\mathrm{VO}_{2}$ at a critical transition temperature of $68{ }^{\circ} \mathrm{C}$, which is accompanied by the modulation of solar irradiation, especially in the near-infrared region. As for commercial applications in our daily life, there are still some obstacles for $\mathrm{VO}_{2}$-based smart coatings, such as the high phase transition temperature, optical properties (luminous transmittance and solar modulation ability), environmental stability in a long-time period, as well as mass production. In this review, recent progress of thermochromic smart coatings to solve above obstacles has been surveyed. Meanwhile, future development trends have also been given to promote the goal of commercial production of $\mathrm{VO}_{2}$ smart coatings.
\end{abstract}

Xun Cao

caoxun2015@gmail.com

1 State Key Laboratory of High Performance Ceramics and Superfine Microstructure, Shanghai Institute of Ceramics, Chinese Academy of Sciences, Shanghai 200050, People's Republic of China

2 Research Center for Industrial Ceramics, Shanghai Institute of Ceramics, Chinese Academy of Sciences, Shanghai 200050, People's Republic of China

3 University of Chinese Academy of Sciences, Beijing 100049, People's Republic of China

4 School of Materials Science and Engineering, Shanghai University, Shanghai 200444, People's Republic of China

5 National Institute of Advanced Industrial Science and Technology (AIST), Moriyama, Nagoya 463-8560, Japan
Keywords Vanadium dioxide $\left(\mathrm{VO}_{2}\right)$ - Thermochromic . Multilayer films $\cdot$ Nanoparticles $\cdot$ Commercial production

\section{Introduction}

Due to environmental deterioration and energy shortage in human society, people pay more attention to finding effective energy efficient materials to reduce the energy consumption and greenhouse gas emission. According to the survey, buildings are responsible for about $40 \%$ of the energy consumption and almost $30 \%$ of the anthropogenic greenhouse gas emissions, which are owing to the use of lighting, air-conditioning, and heating [1-5]. This has driven an urgent demand and research for energy efficient applications to reduce the building energy consumption. The heat exchange between the interior of the building and the outdoor environment through fenestrations leads to the largest energy consumption of buildings. Therefore, managing heat exchange through fenestrations is a feasible approach to reduce the building energy consumptions. In summers, solar radiation entering buildings should be controlled to reduce the air-conditioning energy consumption. On the contrary, thermal radiations from the buildings must be limited to consume lesser energy for heating in winters.

An effective way to achieve this goal would be using smart coatings on building fenestrations to control the solar radiation and thermal radiation. Therefore, smart coatings based on electrochromism [6-10], thermochromism [11-19], gasochromism [20-22] and photochromism [23-26] have been widely studied for energy efficient coatings. Thermochromic smart coatings can modulate near-infrared radiation from transmissive to opaque in response to the environmental temperature from low to 
high, which does not require extra stimuli and can save more energy consumption.

Vanadium dioxide $\left(\mathrm{VO}_{2}\right)$ is a typical thermochromic material that has been widely studied. $\mathrm{VO}_{2}$ exhibits an automatic reversible semiconductor-metal phase transition (SMT) at a critical transition temperature $\left(T_{\mathrm{c}}\right)$ of $68{ }^{\circ} \mathrm{C}$ [27], which has been widely investigated as smart coatings for buildings fenestrations [28-32]. As shown in Fig. 1, for temperatures below the $T_{\mathrm{c}}, \mathrm{VO}_{2}$ is monoclinic $\left(\mathrm{P} 2{ }_{1} / c, \mathrm{M} 1\right)$ phase with the transmittance of infrared (IR) radiation. On the contrary, the material is a tetragonal structure $\left(\mathrm{P}_{2} /\right.$ $m n m, \mathrm{R})$, which is reflective for IR radiation $[33,34]$. This feature makes $\mathrm{VO}_{2}$ an amazing material for thermochromic smart coatings [34-42].

$\mathrm{VO}_{2}$ smart coatings are usually used in two forms including flexible foils based on $\mathrm{VO}_{2}$ nanoparticles [31, 43-49] and $\mathrm{VO}_{2}$ based multilayer films [11, 12, 30, 50-52]. However, for commercial application as smart coatings on energy efficient fenestrations, there are still several obstacles severely limiting the relative applicability of $\mathrm{VO}_{2}$ smart coatings. (i) The phase transition temperature $\left(T_{\mathrm{c}}\right)$ for pure bulk $\mathrm{VO}_{2}\left(68^{\circ} \mathrm{C}\right)$ is too high to be applied on building fenestrations, while $T_{\mathrm{c}}$ around $40{ }^{\circ} \mathrm{C}$ is acceptable. (ii) For conventional $\mathrm{VO}_{2}$ coatings, relative modulation abilities are not efficient enough for energy saving. That can be explained by the fact that the modulation of $\mathrm{VO}_{2}$ for solar radiation is most attributed to the transmittance switch in the near-infrared region, which only accounts for $43 \%$ of solar energy in the solar spectrum [23]. (iii) The luminous transmittance $T_{\text {lum }}$ for single layer $\mathrm{VO}_{2}$ with desirable $\left(\Delta T_{\text {sol }}\right)$ is usually less than $40 \%$ (even $30 \%$ ) due to the absorption in the short-wavelength range in both the semiconducting and metallic states of $\mathrm{VO}_{2}$, which should be larger than $50 \%$ at least for daily applications. (iv) For practical applications as smart coatings, $\mathrm{VO}_{2}$ must maintain excellent thermochromic performances during a long-time period-at least ten years. However, $\mathrm{VO}_{2}$ will finally transform into the $\mathrm{V}_{2} \mathrm{O}_{5}$ phase in the real environment, which is the most thermodynamically stable phase of vanadium oxide but does not possess the

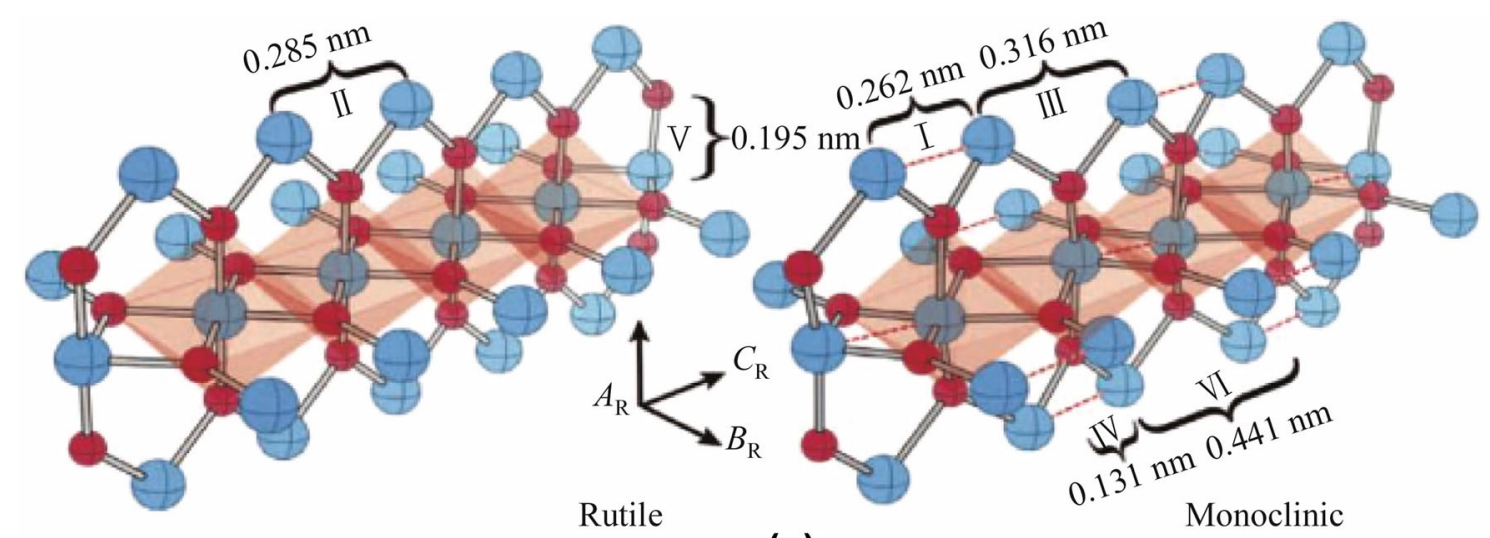

(a)

Below transition temperature

Above transition temperature

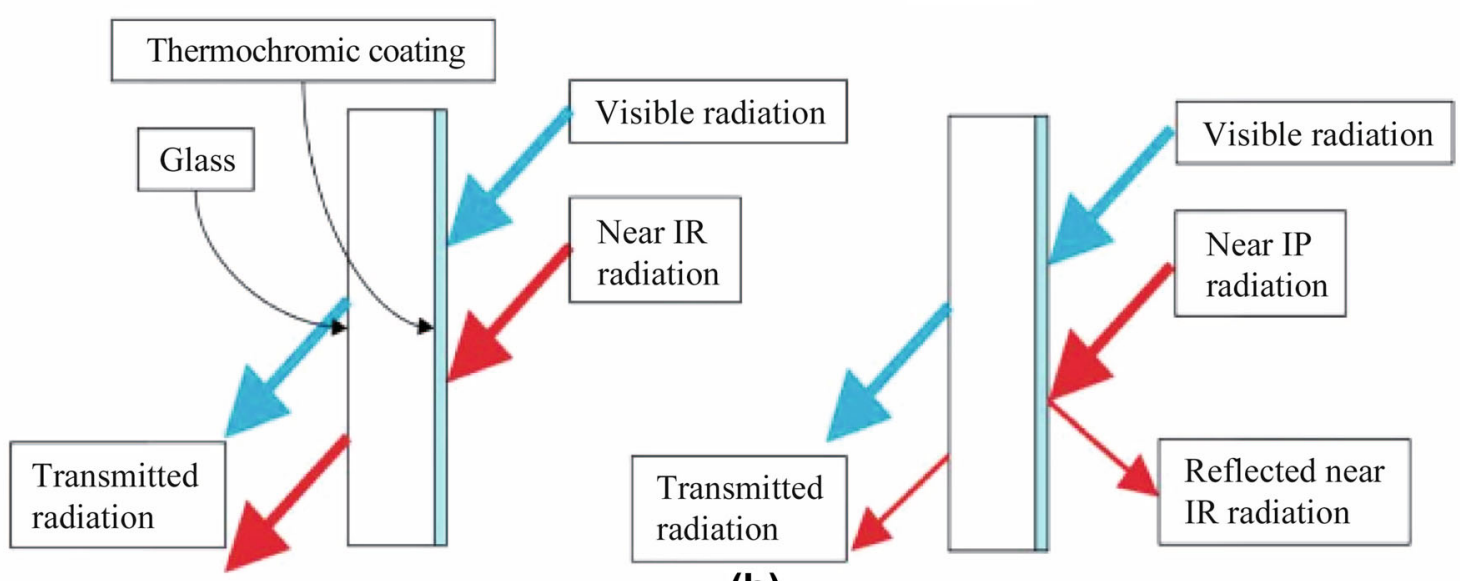

(b)

Fig. 1 a The crystallographic structure of $\mathrm{VO}_{2}$ (rutile) and $\mathrm{VO}_{2}$ (monoclinic) [53] and $\mathbf{b}$ schematic of thermochromic behavior before and after the phase transition [33] 
thermochromic property [54]. Therefore, environmental stability of $\mathrm{VO}_{2}$ is a great challenge for practical applications as smart coatings.

These obstacles must be overcome for practical applications and many efforts have been made to achieve this goal. Doping of proper ions can effectively reduce the phase transition temperature of $\mathrm{VO}_{2}$ : cations larger than $\mathrm{V}^{4+}$, such as $\mathrm{W}^{6+}[55], \mathrm{Mo}^{6+}[56]$ and $\mathrm{Nb}^{5+}[57]$, and anions smaller than $\mathrm{O}^{2-}$, such as $\mathrm{F}^{-}$[58], have been utilized to reduce the $T_{\mathrm{c}}$. However, obstacles in (ii)-(iv) have not been solved. Although several reviews about $\mathrm{VO}_{2}$ coatings have been reported [32, 33, 59, 60], most of them are still in lab scale and few prospects of commercial applications are available.

In this review, we are going to view strategies of thermochromic $\mathrm{VO}_{2}$ smart coatings for improved thermochromic performance, environmental stability and large-scale production for commercial applications on building fenestrations. Firstly, strategies to enhance thermochromic performance ( $T_{\text {lum }}$ and $\left.\Delta T_{\text {sol }}\right)$ of $\mathrm{VO}_{2}$ coatings have been introduced as well as the balance between $T_{\text {lum }}$ and $\Delta T_{\text {sol }}$ (Section 2). Then, methods to improve the durability of $\mathrm{VO}_{2}$ coatings, including protective layers for multilayer films and core-shell structures for nanoparticles, will be summarized in Section 3. Meanwhile, multifunctional design of $\mathrm{VO}_{2}$ smart coatings such as photocatalysis and self-cleaning function has been discussed in Section 4. Recent progress for large-scale production of $\mathrm{VO}_{2}$ smart coatings has been surveyed in Section 5. Finally, future development trends of $\mathrm{VO}_{2}$ coatings have prospected for large-scale production as practical and commercial applications.

\section{Improvements of optical properties}

$T_{\text {lum }}$ and $\Delta T_{\text {sol }}$ are the most important indexes of thermochromic properties for $\mathrm{VO}_{2}$ smart coatings. The integral $T_{\text {lum }}$ and $T_{\text {sol }}$ of the samples can be obtained by the following equations

$T_{\text {lum }, \text { sol }}=\int \Phi_{\text {lum }, \text { sol }}(\lambda) T(\lambda) \mathrm{d} \lambda / \int \Phi_{\text {lum }, \text { sol }}(\lambda) \mathrm{d} \lambda$,

where $T(\lambda)$ represents the transmittance at wavelength $\lambda$; $\Phi_{\text {lum }}$ is the standard efficiency function for photopic vision; and $\Phi_{\text {sol }}$ is the solar irradiance spectrum for an air mass of 1.5 , which corresponds to the sun standing $37^{\circ}$ above the horizon. While the $\Delta T_{\text {sol }}$ of the films was calculated by $\Delta T_{\text {sol }}=T_{\text {sol, lt }}-T_{\text {sol,ht }}$, where lt and ht represent low temperature and high temperature, respectively.

$\mathrm{VO}_{2}$ smart coatings always suffer from the problem of low luminous transmittance due to the absorption in the short-wavelength range in both the semiconducting and the metallic states [61]. The luminous transmittance of $\mathrm{VO}_{2}$ coatings is largely dependent on relative thicknesses. Based on optical calculation, a single layer $\mathrm{VO}_{2}$ film $(80 \mathrm{~nm})$, for example, exhibits an integrated $T_{\text {lum }}$ of $30.2 \%$ and $25.1 \%$ for semiconducting and metallic $\mathrm{VO}_{2}$ (see Fig. 2a). As for solar modulation ability, the majority of reported modulation abilities are less than $10 \%$, which are not efficient enough for energy saving function [62-65]. For $\mathrm{VO}_{2}$ coatings before and after the phase transition, the contrast of relative optical transmittance is mainly in the near-infrared region (780-2 $500 \mathrm{~nm}$ ), which only accounts for $43 \%$ of solar energy in the solar spectrum (see Fig. 2b).

\subsection{Strategies for enhanced luminous transmittance and solar modulation ability}

Many efforts have been made to improve the luminous transmittance and solar modulation ability of $\mathrm{VO}_{2}$ based smart coatings. For $\mathrm{VO}_{2}$ films fabricated by deposition, the design of multilayer structures is an effective way to improve the optical properties $[11,52,66]$. As for $\mathrm{VO}_{2}$ nanoparticles prepared by solution methods, the formation of composite films is the most commonly used strategy $[67,68]$.

\subsubsection{Multilayer design for $\mathrm{VO}_{2}$ thin films}

Thermochromic smart coatings incorporating $\mathrm{VO}_{2}$ films with additional layers have been fabricated for improved thermochromic performances including desirable luminous transmittance and effective solar modulation ability. Schematic illustration of additional layers such as antireflection layers and buffer layers have been shown in Fig. 3 with three typical structures for $\mathrm{VO}_{2}$ thin films and relative SEM images.

An effective way to improve the luminous transmittance of $\mathrm{VO}_{2}$ coatings is to introduce an antireflection (AR) layer, such as $\mathrm{SiO}_{2}$ [69-72], $\mathrm{TiO}_{2}$ [73], $\mathrm{ZrO}_{2}$ [74], etc. Lee and Cho $[70,71]$ reported that $\mathrm{SiO}_{2}$ antireflection layer successfully increased the luminous transmittance of the $\mathrm{VO}_{2}$ films. However, the luminous transmittance is still not sufficient. $\mathrm{TiO}_{2}$ was selected as $\mathrm{AR}$ layer for $\mathrm{VO}_{2}$ films [73] because $\mathrm{TiO}_{2}$ has a higher refractive index and is a more effective antireflection material for $\mathrm{VO}_{2}$ than the reported $\mathrm{SiO}_{2}$. The optimized $\mathrm{VO}_{2} / \mathrm{TiO}_{2}$ structure has been fabricated and demonstrated the highest $T_{\text {lum }}$ improvement among the reported at that time. The optical calculation was performed upon a basic structure of a $\mathrm{VO}_{2}$ layer with an AR layer of refractive index $n$ and thickness $d$ [74]. Optimization was carried out on $n$ and $d$ for a maximum integrated $T_{\text {lum. }}$. The calculation demonstrates that the optimal $n$ value changes with the thickness of $\mathrm{VO}_{2}$, and at $n \approx 2.2$ it gives the highest $T_{\text {lum }}$ enhancement from $32 \%$ 


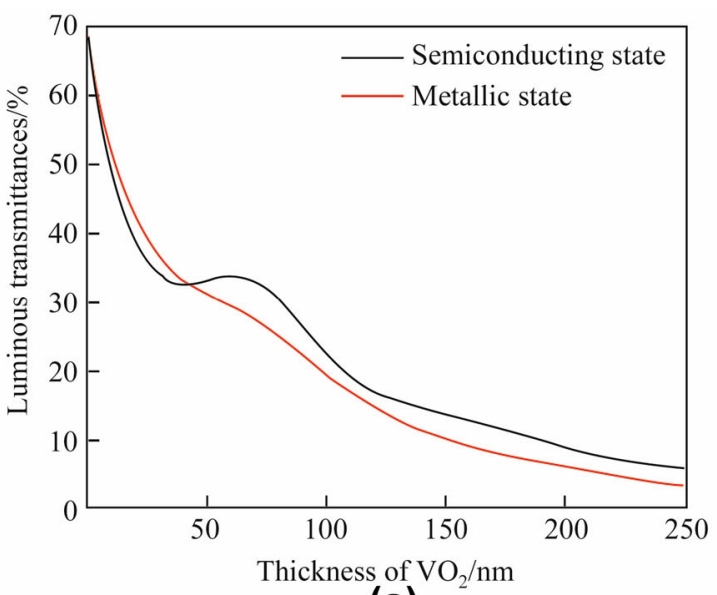

(a)

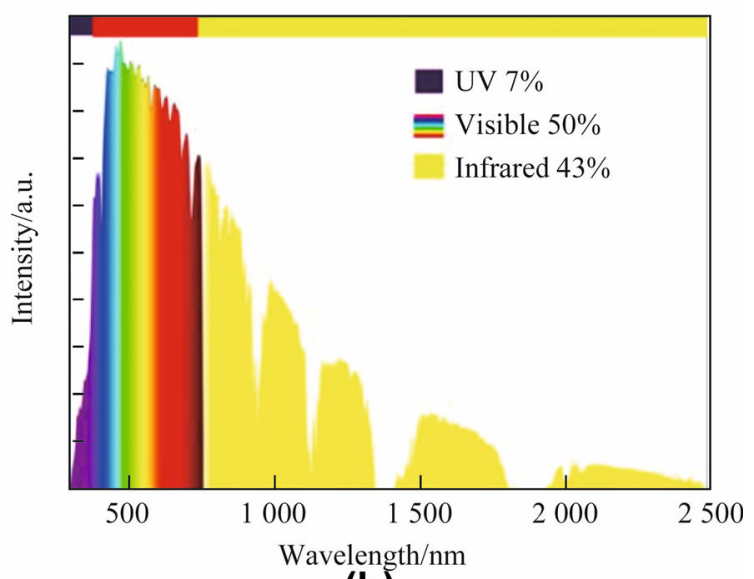

(b)

Fig. 2 a Calculated luminous transmittance for single layer $\mathrm{VO}_{2}$ films with various thicknesses at semiconducting state (black line) and metallic state (red line) and $\mathbf{b}$ the solar spectrum and relative energy distribution [23]

\begin{tabular}{|c|}
\hline Antireflection layer \\
\hline $\mathrm{VO}_{2}$ layer \\
\hline Substrates \\
\hline
\end{tabular}

(a)

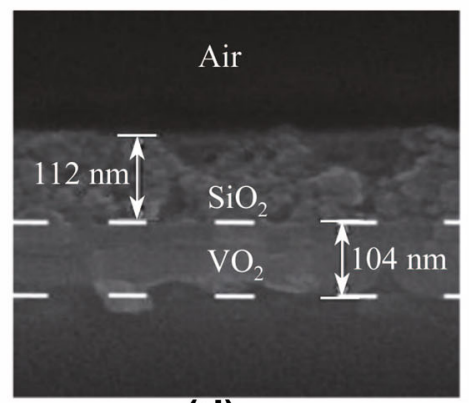

(d)

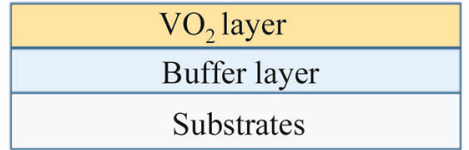

(b)

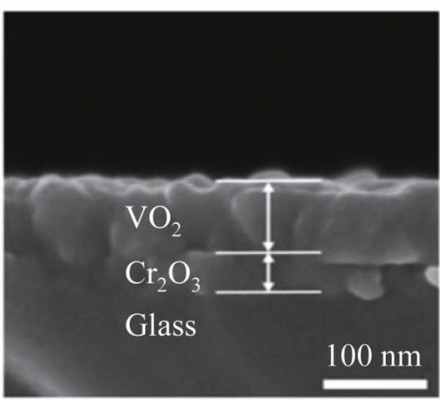

(e)

\begin{tabular}{|c|}
\hline Antireflection layer \\
\hline $\mathrm{VO}_{2}$ layer \\
\hline Buffer layer \\
\hline Substrates \\
\hline
\end{tabular}

(c)

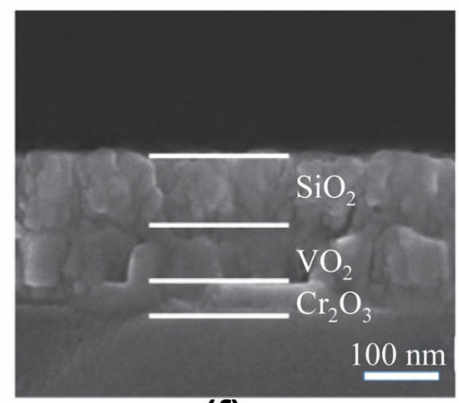

(f)

Fig. 3 Schematic illustration of $\mathrm{VO}_{2}$ based films with a antireflection layer, $\mathbf{b}$ buffer layer, and $\mathbf{c}$ both of antireflection layer and buffer layers, respectively. Relative SEM images of three typical structures have been shown in Figs. d-f corresponding to Figs. a-c [12, 30, 69], respectively

(without AR coating) to $55 \%$ for $50 \mathrm{~nm} \mathrm{VO}_{2}$. They deposited an optimized structure of $\mathrm{VO}_{2} / \mathrm{ZrO}_{2}$ and an improvement from $32.3 \%$ to $50.5 \%$ in $T_{\text {lum }}$ was confirmed for the semiconductor phase of $\mathrm{VO}_{2}$, which was in good agreement with the calculations.

Besides the antireflection layers on the top of $\mathrm{VO}_{2}$ films, buffer layers between the substrates and $\mathrm{VO}_{2}$ films also play important roles in the optical performances of integrated coatings. Some buffer layers as $\mathrm{SiO}_{2}, \mathrm{TiO}_{2}, \mathrm{SnO}_{2}$, $\mathrm{ZnO}, \mathrm{CeO}_{2}$, and $\mathrm{SiN}_{x}$ have been investigated in reported works [75-78]. Nevertheless, thermochromic performances of $\mathrm{VO}_{2}$ coatings obtained based on above buffer layers are fair, which still can not match the requirements for practical applications.
In our recent work, $\mathrm{Cr}_{2} \mathrm{O}_{3}$ has been selected to act as a structural template for the growth of $\mathrm{VO}_{2}$ films as well as the AR layer for improving the luminous transmittance [12]. The suitable refractive index (2.2-2.3) is predicted to be beneficial for the optical performance of $\mathrm{VO}_{2}$ thin films. Refractive index of $\mathrm{Cr}_{2} \mathrm{O}_{3}$ is between the glass and the $\mathrm{VO}_{2}$, which is considered to enhance the luminous transmittance. Meanwhile, $\mathrm{Cr}_{2} \mathrm{O}_{3}$ has similar lattice parameters with $\mathrm{VO}_{2}(\mathrm{R})$, which can act as the structural template layer to lower the lattice mismatch between $\mathrm{VO}_{2}$ thin films and glass substrates and to reduce the deposition temperature of $\mathrm{VO}_{2}$ thin films (see Figs. 4a, b). Different crystallization of $\mathrm{VO}_{2}$ films can be obtained by introducing $\mathrm{Cr}_{2} \mathrm{O}_{3}$ layers with various thicknesses at a competitive temperature 


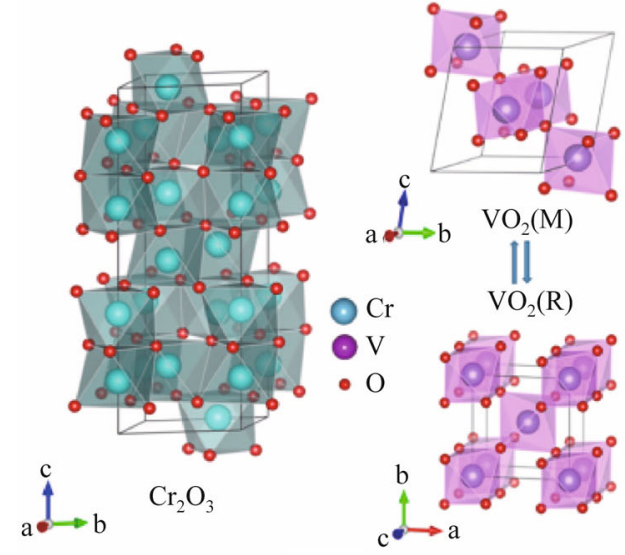

(a)

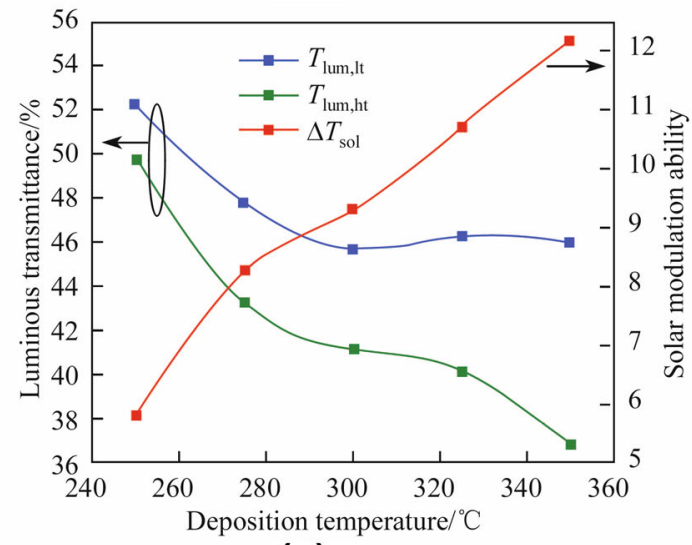

(c)

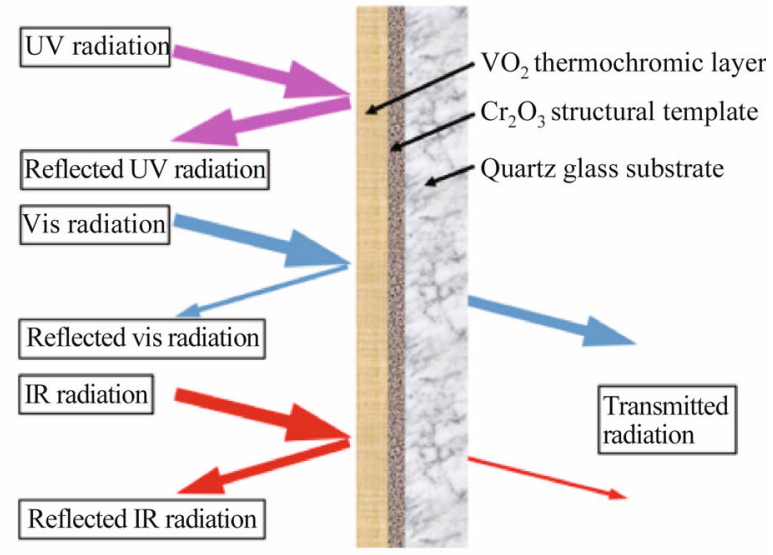

(b)

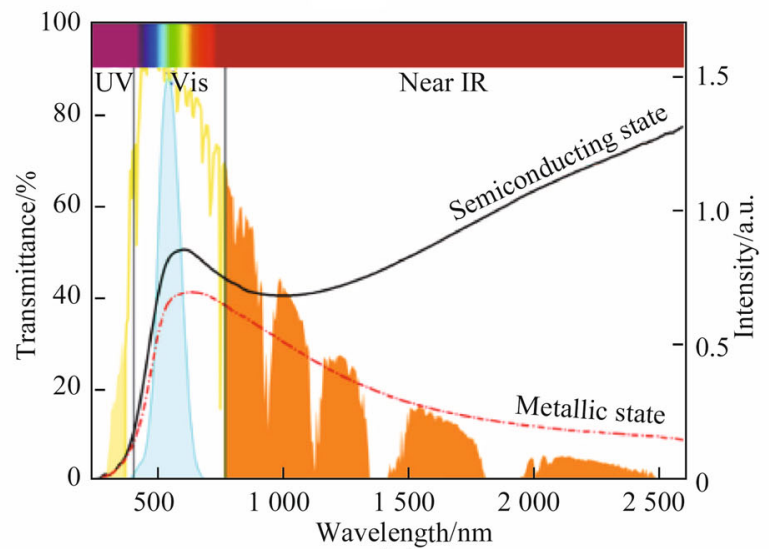

(d)

Fig. 4 a Crystal structure of hexagonal $\mathrm{Cr}_{2} \mathrm{O}_{3}$, monoclinic $\mathrm{VO}_{2}$, and rutile $\mathrm{VO}_{2}$, respectively, b schematic illustration of $\mathrm{Cr}_{2} \mathrm{O}_{3} / \mathrm{VO}_{2}$ bilayer thermochromic film, $\mathbf{c}$ variation curve of $T_{\text {lum,lt }}, T_{\text {lum,ht }}$ and $\Delta T_{\text {sol }}$ for $\mathrm{VO}_{2}$ films deposited with $40 \mathrm{~nm} \mathrm{Cr}_{2} \mathrm{O}_{3}$ structural template layer at different temperatures, $\mathbf{d}$ transmittance spectra $(250-2600 \mathrm{~nm})$ at $25{ }^{\circ} \mathrm{C}$ and $90{ }^{\circ} \mathrm{C}$ for $\mathrm{VO}_{2}$ films deposited with $40 \mathrm{~nm} \mathrm{Cr}_{2} \mathrm{O}_{3}$ structural template layer at $350{ }^{\circ} \mathrm{C}$ and standard solar spectra [12]

range from $250{ }^{\circ} \mathrm{C}$ to $350{ }^{\circ} \mathrm{C}$, where different thermochromic performance can be obtained (see Fig. 4c). The $\mathrm{Cr}_{2} \mathrm{O}_{3} / \mathrm{VO}_{2}$ bilayer film deposited at $350{ }^{\circ} \mathrm{C}$ with optimal thickness shows an excellent $\Delta T_{\text {sol }}=12.2 \%$ with an enhanced $T_{\text {lum.lt }}=46.0 \%$ (see Fig. $4 \mathrm{~d}$ ), while the value of $\Delta T_{\text {sol }}$ and $T_{\text {lum.lt }}$ for the single layer $\mathrm{VO}_{2}$ film deposited high temperature at $450{ }^{\circ} \mathrm{C}$ is $7.8 \%$ and $36.4 \%$, respectively. The $\mathrm{Cr}_{2} \mathrm{O}_{3}$ insertion layer dramatically increased the visible light transmission, as well as improved the solar modulation of the original films, which arised from the structural template effect and antireflection function of $\mathrm{Cr}_{2} \mathrm{O}_{3}$ to $\mathrm{VO}_{2}$.

For better thermochromic performance, sandwich structures based on $\mathrm{VO}_{2}$ films have been fabricated. Double-layer antireflection incorporating $\mathrm{TiO}_{2}$ and $\mathrm{VO}_{2}\left(\mathrm{TiO}_{2} /\right.$ $\mathrm{VO}_{2} / \mathrm{TiO}_{2}$ ) has been proposed [61] and a maximum increase in $T_{\text {lum }}$ by $86 \%$ (from $30.9 \%$ to $57.6 \%$ ) has been obtained, which is better than the sample with single-layer antireflection (49.1\%) [73]. The same structure of $\mathrm{TiO}_{2} /$
$\mathrm{VO}_{2} / \mathrm{TiO}_{2}$ has also been investigated by Zheng et al. [11] and Sun et al. [35] for improved thermochromic performance and skin comfort design. A novel sandwich structure of $\mathrm{VO}_{2} / \mathrm{SiO}_{2} / \mathrm{TiO}_{2}$ has been described by Powell et al. [66], where the $\mathrm{SiO}_{2}$ layers acts as ion-barrier interlayers to prevent diffusion of $\mathrm{Ti}$ ions into the $\mathrm{VO}_{2}$ lattice. The best performing multilayer film obtained in this work showed an excellent solar modulation ability (15.29\%), which was very close to the maximum possible solar modulation for $\mathrm{VO}_{2}$ thin films. Unfortunately, the corresponding luminous transmittance is weak of around $18 \%$ for both semiconducting and metallic states.

A novel $\mathrm{Cr}_{2} \mathrm{O}_{3} / \mathrm{VO}_{2} / \mathrm{SiO}_{2}$ (CVS) sandwich structures have been proposed and fabricated based on optical design and calculations [30]. The bottom $\mathrm{Cr}_{2} \mathrm{O}_{3}$ layer provides a structural template for improving the crystallinity of $\mathrm{VO}_{2}$ and increasing the luminous transmittance of the structure. Then, the $\mathrm{VO}_{2}$ layer with a monoclinic (M) phase at low temperature undergoes a reversible phase-transition to 
rutile $(\mathrm{R})$ phase at high temperature for solar modulation. The top $\mathrm{SiO}_{2}$ layer not only acts as an antireflection layer but also greatly enhances the environmental stability of the multilayer structures as well as providing a self-cleaning layer for the versatility of smart coatings. Optical simulation of luminous transmittances (semiconducting state) for the CVS structure has been shown in Fig. 5a (3-dimensional image). The thickness of the $\mathrm{VO}_{2}$ layer was fixed at $80 \mathrm{~nm}$ to demonstrate significant thermochromic performance while varying thicknesses of $\mathrm{Cr}_{2} \mathrm{O}_{3}$ and $\mathrm{SiO}_{2}$ were investigated for optimized optical properties. Four clear peaks are observed in the luminous transmittance simulations, which can be attributed to the interference effect of the multilayer structure. The highest value of $T_{\text {lum,lt }}$ is about $44.0 \%$ at approximately $40 \mathrm{~nm}$ and $90 \mathrm{~nm}$ of $\mathrm{Cr}_{2} \mathrm{O}_{3}$ and $\mathrm{SiO}_{2}$, respectively. In this work, the proposed CVS multilayer thermochromic film shows an ultrahigh $\Delta T_{\text {sol }}=16.1 \%$ with an excellent $T_{\text {lum,lt }}=54.0 \%$, which gives acommendable balance between $\Delta T_{\text {sol }}$ and $T_{\text {lum.lt }}$ (see Figs. $5 b, c)$. The demonstrated structure shows the best optical performance in the reported structures grown by magnetron sputtering and even better than most of the structures fabricated by solution methods. To date, the proposed CVS structure exhibits the most recommendable balance between the solar modulation ability and the luminous transmittance to reported $\mathrm{VO}_{2}$ multilayer films (see Fig. 5d).

There is some work focus on multilayer films with more layers for enhanced thermochromic performances. A fivelayer thermochromic coating based on $\mathrm{TiO}_{2} / \mathrm{VO}_{2} / \mathrm{TiO}_{2} /$ $\mathrm{VO}_{2} / \mathrm{TiO}_{2}$ has been studied [52]. A featured wave-like optical transmittance curve has been measured by the fivelayer coating companying an improved luminous transmittance $(45.0 \%$ at semiconducting state) and a competitive solar modulation ability (12.1\%). Multilayer structure like $\quad \mathrm{SiN}_{x} / \mathrm{NiCrO}_{x} / \mathrm{SiN}_{x} / \mathrm{VO}_{x} / \mathrm{SiN}_{x} / \mathrm{NiCrO}_{x} / \mathrm{SiN}_{x}$ exhibits

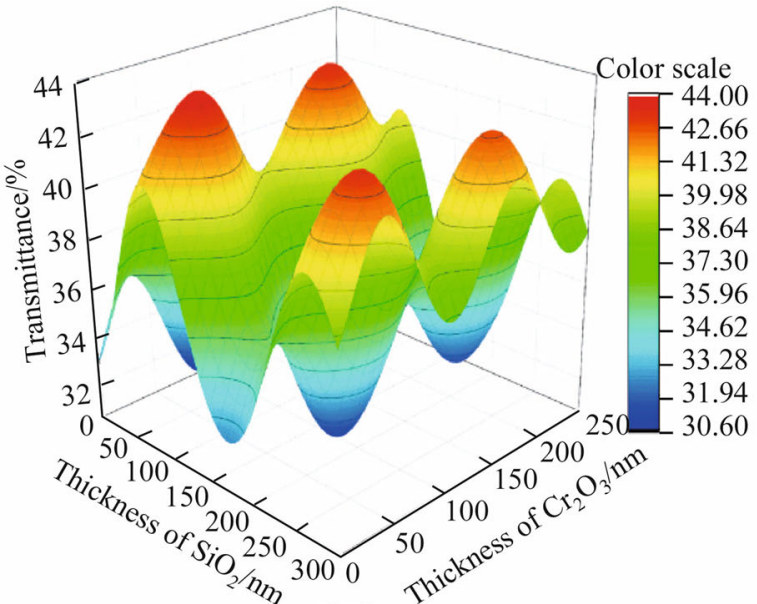

(a)

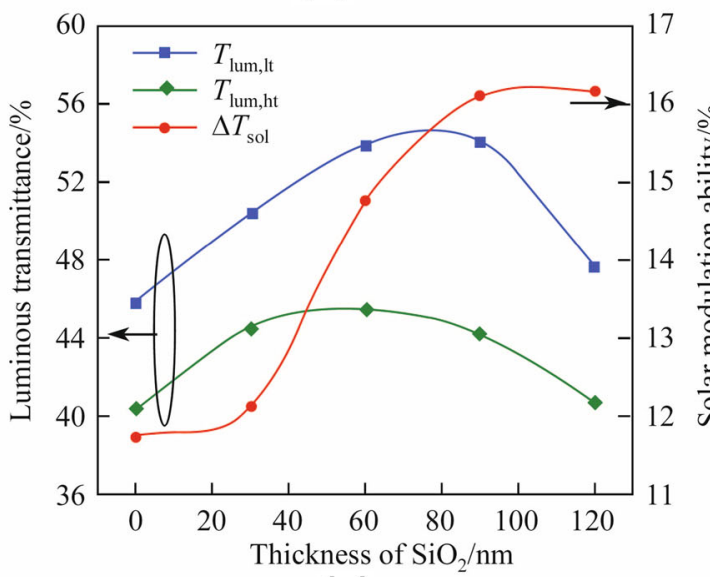

(c)

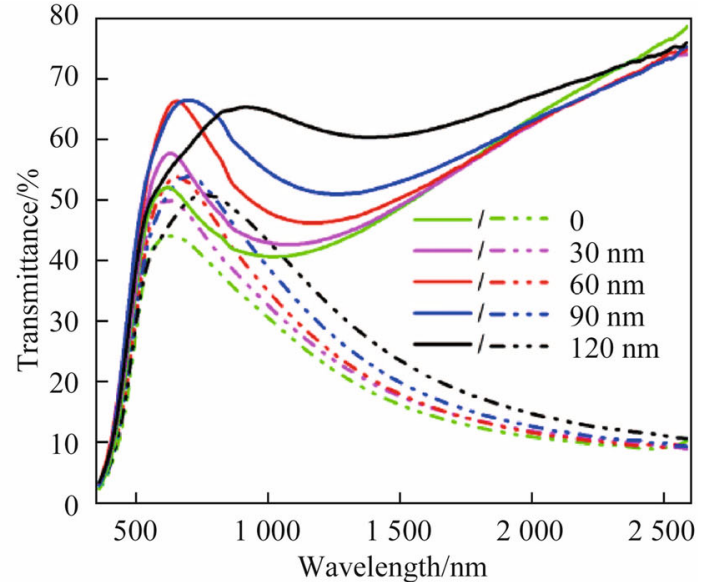

(b)

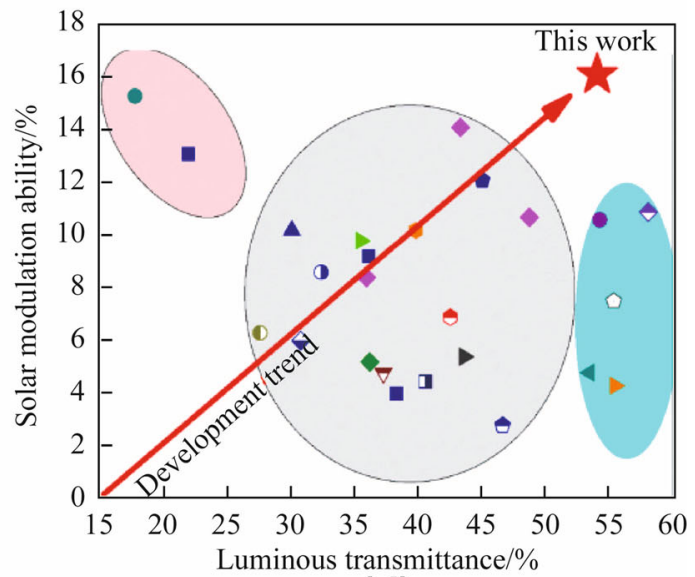

(d)

Fig. 5 a $3 \mathrm{D}$ surface image of the luminous transmittance $\left(T_{\text {lum,lt }}\right)$ calculation of the $\mathrm{Cr}_{2} \mathrm{O}_{3} / \mathrm{VO}_{2}(80 \mathrm{~nm}) / \mathrm{SiO}_{2}$ multilayer structure on the thickness design of $\mathrm{Cr}_{2} \mathrm{O}_{3}$ (bottom layer) and $\mathrm{SiO}_{2}$ (top layer), $\mathbf{b}$ transmittance spectra $\left(350-2600 \mathrm{~nm}\right.$ ) at $25^{\circ} \mathrm{C}$ (solid lines) and $90{ }^{\circ} \mathrm{C}$ (dashed lines) for the CVS structures with various thicknesses of $\mathrm{SiO}_{2}$ layers, $\mathbf{c}$ corresponding variation curves of $T_{\text {lum,lt }}, T_{\text {lum.ht }}$, and $\Delta T_{\mathrm{sol}}$ for $\mathbf{b}$, d comparison of this work with recently reported $\mathrm{VO}_{2}$-based thermochromic films [30] 
superior solar modulation ability of $18.0 \%$, but the luminous transmittance $(32.7 \%)$ and the complicated structure pose an enormous obstacle for practical application of this structure.

\subsubsection{Composite films based on $\mathrm{VO}_{2}$ nanoparticles}

Composite films incorporating $\mathrm{VO}_{2}$ nanoparticles with inorganic or/and organic materials have many advantages. On the one hand, the structure of composite films may induce strains, which may have positive effects on the $T_{\mathrm{c}}$ and hysteresis-loop width of $\mathrm{VO}_{2}$ films [79]. On the other hand, according to the optical calculations performed by $\mathrm{Li}$ et al. [80], $\mathrm{VO}_{2}$ nanoparticles dispersed in suitable dielectric hosts show much higher luminous transmittance and solar energy transmittance modulation than pure $\mathrm{VO}_{2}$ films [80].

$\mathrm{VO}_{2}-\mathrm{ZrV}_{2} \mathrm{O}_{7}$ composite films have been successfully prepared by polymer-assisted deposition using $\mathrm{V}-\mathrm{Zr}-\mathrm{O}$ solution [79]. With similar thickness, the composite films exhibited significantly enhanced luminous transmittances with increasing $\mathrm{Zr} / \mathrm{V}$ ratios (from $32.3 \%$ at $\mathrm{Zr} / \mathrm{V}=0$ to $53.4 \%$ at $\mathrm{Zr} / \mathrm{V}=0.12$ ), which can be attributed to the absorption-edge changes in the composite films. Nevertheless, the solar modulation ability of the samples showed slightly weakened increasing $\mathrm{Zr} / \mathrm{V}$ ratios (from $6.0 \%$ at $\mathrm{Zr}$ / $\mathrm{V}=0$ to $4.8 \%$ at $\mathrm{Zr} / \mathrm{V}=0.12$ ). Crystallized $\mathrm{TiO}_{2}-\mathrm{VO}_{2}$ composite films were prepared by dispersing $\mathrm{VO}_{2}$ nanoparticles in $\mathrm{TiO}_{2}$ sol and annealing by an optimized two-step annealing process [81]. The optical performance of these composite films could be improved by increasing their porosity by controlling annealing rate or by introducing mesopores.

Inorganic host $\mathrm{BaSO}_{4}$ has also been investigated due to its numerous advantages, such as stronger chemical inertness, acid and alkali resistance, relatively high density and whiteness, especially the high dispersion, good refractive index and transparency [82]. $\mathrm{VO}_{2}-\mathrm{BaSO}_{4}$ composite powders were prepared by a one-step hydrothermal process, and the existence of the $\mathrm{BaSO}_{4}$ could improve the optical properties of the $\mathrm{VO}_{2}$ by $43.0 \%$ in $T_{\text {lum }}$ (from $30.4 \%$ to $43.5 \%$ ) and $10.7 \%$ in $\Delta T_{\text {sol }}$ (from $11.2 \%$ to $12.4 \%$ ).

Besides the inorganic hosts as $\mathrm{ZrV}_{2} \mathrm{O}_{7}, \mathrm{TiO}_{2}$, and $\mathrm{BaSO}_{4}$, organic hosts also show great potentials in smart coatings. A temperature-responsive hydrogel based on poly $(N$-iso-propylacrylmide) (PNIPAm) has been reported [83]. The PNIPAm can undergo a hydrophilic to hydrophobic transition at the lower critical solution temperature (LCST). By tuning the thickness of the hydrogel and designing a suitable glass panel set-up, the PNIPAm exhibited an unprecedented good combination of the neardoubled average $T_{\text {lum }}(70.7 \%)$, higher $\Delta T_{\text {sol }}(25.5 \%)$ and lower transition temperature $\left(32^{\circ} \mathrm{C}\right)$. Further investigations have been carried out by dispersing $\mathrm{VO}_{2}$ nanoparticles into a PNIPAm hydrogel to form a hybrid thermochromic material [67]. The $\mathrm{VO}_{2}$ /hydrogel hybrid nanothermochromic material makes a dramatically higher $\Delta T_{\text {sol }}$ up to $35 \%$, while still maintaining higher average $T_{\text {lum }}(63 \%)$ (see Fig. 6).

Some transition metal complexes (TMCs) that exhibit thermochromism with little $T_{\text {lum }}$ loss at high temperature are chosen to be hybridized with $\mathrm{VO}_{2}$ nanoparticles [45, 68, 84]. The used TMCs can partly absorb visible light and change color as a response to temperature change upon interaction with an appropriate donor solvent and effectively avoid severe damage to $T_{\text {lum }}$ at high temperature because the absorption peaks are staggered with the extremum of the light-adapted eye sensitivity function. The thermochromic ionic liquid (IL) has been used by Zhu et al. [68]. Briefly, when heating from room temperature, the ionic liquid-nickel-chlorine (IL-Ni-Cl) complexes absorb increasing visible light around $656 \mathrm{~nm}$ and $705 \mathrm{~nm}$, and gradually change color from colorless to blue. Compared with a pure $\mathrm{VO}_{2}$ film, the composite film of $\mathrm{VO}_{2}$ nanoparticles and $\mathrm{IL}-\mathrm{Ni}-\mathrm{Cl}$ complexes not only expresses more excellent optical performance $\left(\Delta T_{\mathrm{sol}}=26.45 \%\right.$ and $T_{\text {lum,lt }}=66.44 \%, T_{\text {lum,lt }}=43.93 \%$ ) but also adds a function of an obvious color change from brown to green as temperature rises, facilitating application and function exhibiting of smart windows (see Fig. 7). TMCs like IL$\mathrm{Ni}-\mathrm{Br}$ and IL-Co-Br have also been studied with robust improvements of thermochromic performances of $\mathrm{VO}_{2}$ nanoparticles [45, 84].

\subsection{Balance between luminous transmittances and solar modulation ability}

Regarding practical application of $\mathrm{VO}_{2}$ based thermochromic smart coatings, high solar modulation ability accompanied by high luminous transmittance is required. Nevertheless, we can find that it is tough to make a good balance between luminous transmittance and solar modulation ability. A unilateral pursuit of distinguished solar modulation ability or ultrahigh luminous transmittances is meaningless.

Most work on $\mathrm{VO}_{2}$ based smart coatings pursue large contrast of optical transmittance in the near infrared region (780-2 $500 \mathrm{~nm}$ ), while inconspicuous contrast in the visible light region (380-780 nm) is desirable for both semiconducting and metallic states. In the solar spectrum, ultraviolet light, visible light and infrared light is responsible for about $7 \%, 50 \%, 43 \%$ of solar energy, respectively [23]. Therefore, if there is an increased contrast in the visible light region for $\mathrm{VO}_{2}$ based smart coatings between the semiconducting and the metallic state, relative solar 


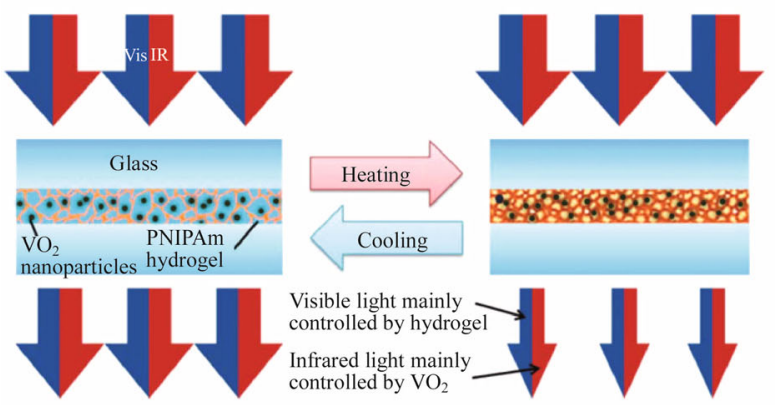

(a)

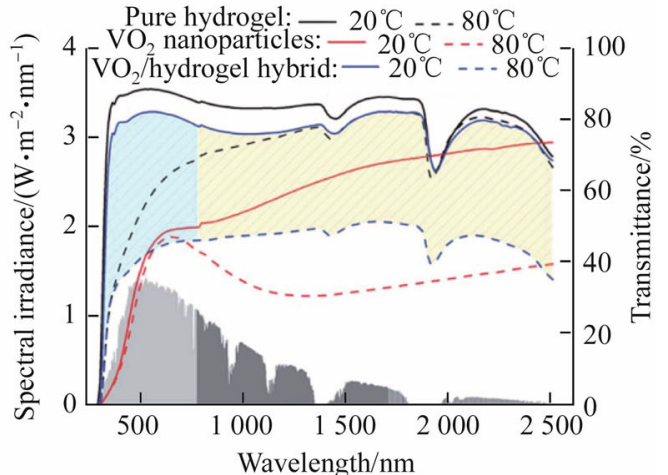

(b)

Fig. 6 a Solar modulation mechanism of the $\mathrm{VO}_{2}$ /hydrogel hybrid, b UV-Vis spectra of pure hydrogel (black), pure $\mathrm{VO}_{2}$ (red), and $\mathrm{VO}_{2} /$ hydrogel hybrid (blue) at low and high temperature (the grey area indicates the normalized values of the visible (light) and IR(dark) spectra spectral irradiance. The light cyan area with sparse slashes is the luminous transmission difference, and the light yellow area is the IR transmission difference of the $\mathrm{VO}_{2}$ /hydrogel hybrid) [67]

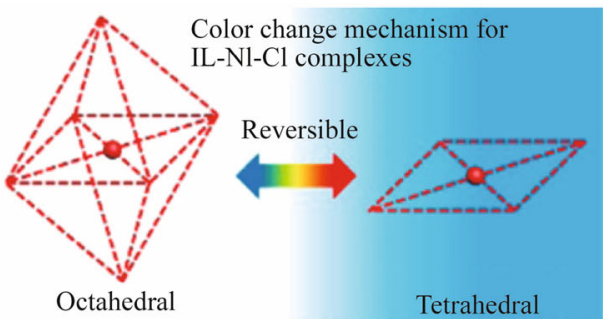

Color change for $\mathrm{VO}_{2} / \mathrm{IL}-\mathrm{Nl}-\mathrm{Cl}$ composite film

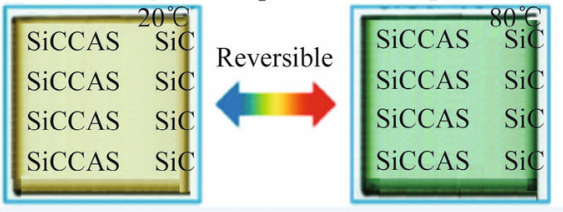

(a)

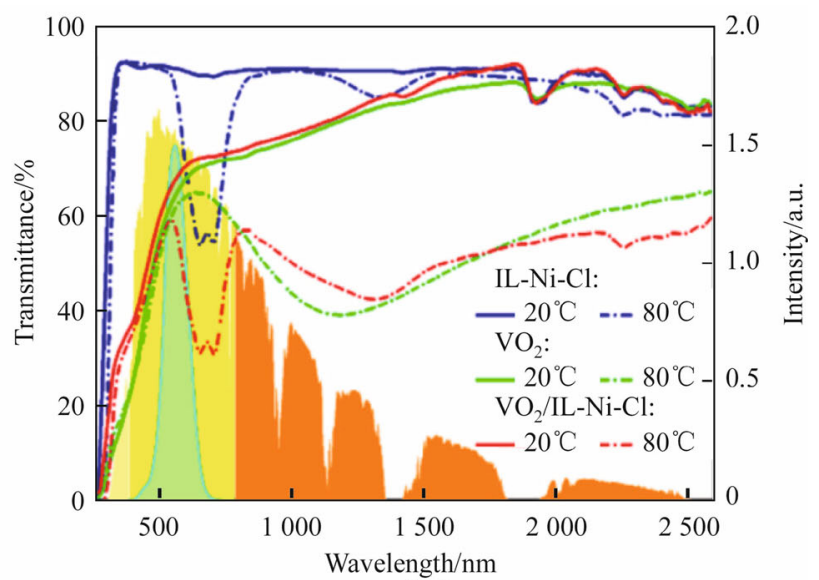

(b)

Fig. 7 a Color change mechanism for IL-Ni-Cl complexes (upper) and color change of $\mathrm{VO}_{2} / \mathrm{IL}-\mathrm{Ni}$-Cl composites film, b UV-Vis-NIR transmittance spectra of pure IL-Ni-Cl complexes film, pure $\mathrm{VO}_{2}$ nanoparticles film, and $\mathrm{VO}_{2} / \mathrm{IL}-\mathrm{Ni}-\mathrm{Cl}$ composite film at $20{ }^{\circ} \mathrm{C}$ and $80{ }^{\circ} \mathrm{C}$ (the yellow-orange area indicates the normalized values of the visible (yellow) and NIR (orange) spectra spectral irradiance, and the cyan area indicates the values of eyes ensitivity function) [68]

modulation ability can be robustly enhanced due to the contribution from the visible light region. That means that the transmittance in the visible light region for $\mathrm{VO}_{2}$ smart coating of metallic state should be maintained at least $50 \%$, while the coating shows higher luminous transmittance of semiconducting state. Some works have been reported to increase $\Delta T_{\text {sol }}$ of $\mathrm{VO}_{2}$ by mixing with specific materials shows a robust contrast in the visible light region in different temperatures [45, 68]. However, more investigations are required for a facile and cheap method to achieve the balance between luminous transmittances and solar modulation ability of $\mathrm{VO}_{2}$ based smart coatings.

\section{Methods to improve the stability of $\mathrm{VO}_{2}$ for long-time use}

In previous work, researchers usually focus on the thermochromic properties of $\mathrm{VO}_{2}$ to improve the luminous transmittances and solar modulation ability. However, environmental stability is another great challenge for $\mathrm{VO}_{2}$ coatings from lab to industrial production. Vanadium is a multivalent element and there are several kinds of vanadium oxide, such as $\mathrm{VO}, \mathrm{V}_{2} \mathrm{O}_{3}, \mathrm{VO}_{2}, \mathrm{~V}_{6} \mathrm{O}_{13}, \mathrm{~V}_{4} \mathrm{O}_{9}, \mathrm{~V}_{3} \mathrm{O}_{7}$, and $\mathrm{V}_{2} \mathrm{O}_{5}$. Among them, $\mathrm{V}_{2} \mathrm{O}_{5}$ is the most thermodynamically stable phase and $\mathrm{VO}_{2}$ will gradually transform into the intermediate phases of $\mathrm{V}_{6} \mathrm{O}_{13}$ and $\mathrm{V}_{3} \mathrm{O}_{7}$ and finally into $\mathrm{V}_{2} \mathrm{O}_{5}$ [54]. However, unlike $\mathrm{VO}_{2}, \mathrm{~V}_{2} \mathrm{O}_{5}$ does not possess thermochromic optical change properties near the room temperature. Therefore, how to maintain the 
thermochromic performance of $\mathrm{VO}_{2}$ coatings during a long-time period is an inevitable problem that must be overcome.

\subsection{Protective layers for $\mathrm{VO}_{2}$ films}

To prevent $\mathrm{VO}_{2}$ films from degradation, introducing of protective layers above $\mathrm{VO}_{2}$ is an effective way that has been widely used. Chemically stable oxide films such as $\mathrm{Al}_{2} \mathrm{O}_{3}$ [54, 85], $\mathrm{CeO}_{2}$ [86, 87], $\mathrm{WO}_{3}$ [64], etc., have been studied to keep $\mathrm{VO}_{2}$ away from oxidant like water and $\mathrm{O}_{2}$ in air. It should be noted that the selected materials to be used as protective layers might affect the optical properties of $\mathrm{VO}_{2}$, where dual enhancement in the optical properties and the stability is preferred.

$\mathrm{Al}$ oxide is a typical material that has been investigated as a protection layer for $\mathrm{VO}_{2}$ coatings. In work reported by $\mathrm{Ji}$ et al. [54], different thicknesses of $\mathrm{Al}$ oxide protective layers have been deposited for $\mathrm{VO}_{2}$ by $\mathrm{DC}$ magnetron sputtering. The durability of the samples was evaluated at a high temperature around $300{ }^{\circ} \mathrm{C}$ in dry air and highly humid environment. They found that the $\mathrm{Al}$ oxide protective layers provided good protection and delayed the degradation process of $\mathrm{VO}_{2}$ in dry air at $300{ }^{\circ} \mathrm{C}$ and humid environment. The similar structure was also investigated [85], while the $\mathrm{Al}_{2} \mathrm{O}_{3}$ protective layers were fabricated by atomic layer deposition (ALD). The $\mathrm{Al}_{2} \mathrm{O}_{3}$ films can protect the $\mathrm{VO}_{2}$ from oxidation in the heating test but not sufficient in the damp environment, which can be attributed to the corrosion of water to $\mathrm{Al}_{2} \mathrm{O}_{3}$. It is worthy to mention that in above cases, the test period of the samples is less than one week $(168 \mathrm{~h})$, which is far from the request for practical applications.

Long et al. [64] proposed a novel sandwich structure of $\mathrm{WO}_{3} / \mathrm{VO}_{2} / \mathrm{WO}_{3}$, where $\mathrm{WO}_{3}$ not only functions as an $\mathrm{AR}$ layer to enhance the $T_{\text {lum }}$ of $\mathrm{VO}_{2}$ but also performs as a good protective layer for thermochromic $\mathrm{VO}_{2}$. The stability of samples was investigated in a constant-temperature humid environment with $90 \%$ relative humidity at $60{ }^{\circ} \mathrm{C}$. For the single layer $\mathrm{VO}_{2}$, the thermochromism nearly vanishes after 20 day treatment in the tough environment. On the contrary, there shows almost no change in the optical transmittance of $\mathrm{WO}_{3} / \mathrm{VO}_{2} / \mathrm{WO}_{3}$ multilayer films with the same treatment. However, though the protection provided by the $\mathrm{WO}_{3}$, the solar modulation ability of the sample is weakly reduced due to the diffusion of $\mathrm{W}^{6+}$ to $\mathrm{VO}_{2}$.

In works above, the protective layers are usually single layer films. To enhance the durability of thermochromic $\mathrm{VO}_{2}$ films, bilayer coatings as $\mathrm{VO}_{2} / \mathrm{TiO}_{2} / \mathrm{ZnO}, \mathrm{VO}_{2} / \mathrm{SiO}_{2} /$ $\mathrm{ZnO}$, and $\mathrm{VO}_{2} / \mathrm{SiO}_{2} / \mathrm{TiO}_{2}$ have been studied [88]. In this study, $\mathrm{VO}_{2}$ films with $\mathrm{TiO}_{2} / \mathrm{ZnO}$ protective coatings have been demonstrated higher antioxidant activity under aging tests, which can be attributed to the different oxygen permeability through different inorganic films [89]. Zhan et al. [90] fabricated a complicated multilayer structure of $\mathrm{SiN}_{x}$ I $\mathrm{NiCrO}_{x} / \mathrm{SiN}_{x} / \mathrm{VO}_{x} / \mathrm{SiN}_{x} / \mathrm{NiCrO}_{x} / \mathrm{SiN}_{x}$, which exhibits enhanced thermal stability up to $375{ }^{\circ} \mathrm{C}$. However, aging test in a humid environment is not applied to the samples.

The $\mathrm{Cr}_{2} \mathrm{O}_{3} / \mathrm{VO}_{2} / \mathrm{SiO}_{2}$ structure proposed by our lab shows robust environmental stability for long-time use [30]. The top $\mathrm{SiO}_{2}$ layer is chemically stable and makes the static water contact angle of the films change abruptly from $24.1^{\circ}$ (hydrophilicity) to $115.0^{\circ}$ (hydrophobicity) (see Figs. 8a, b). Hydrophilicity of the single layer $\mathrm{VO}_{2}$ indicates well contact with water, which will accelerate the degradation process of relative thermochromic performance. On the contrary, the hydrophobicity that exhibited by the CVS structure is helpful to keep the $\mathrm{VO}_{2}$ isolated from the water, which can protect the coatings against oxidation. Wettability is dependent on the chemical composition and structure of the surface. The surface of silicon is normally hydrophilic without additional treatments, but previous studies have demonstrated that the wettability of the silicon surface can be significantly changed by structuring the surfaces. So, fabrication of $\mathrm{SiO}_{2}$ top coatings in this work has been deliberately optimized with enhanced roughness for hydrophobic surfaces (see Fig. 8b). The double-protection from $\mathrm{Cr}_{2} \mathrm{O}_{3}$ and $\mathrm{SiO}_{2}$ makes an excellent promotion for the environmental stability of the CVS coatings, which is desirable for long-time use. The proposed CVS structure shows remarkable environmental stability due to the dual-protection from the $\mathrm{Cr}_{2} \mathrm{O}_{3}$ and the $\mathrm{SiO}_{2}$ layer, which shows negligible deterioration even after accelerated aging $\left(60{ }^{\circ} \mathrm{C}\right.$ and $90 \%$ relative humidity) of $10^{3} \mathrm{~h}$ and $4 \times 10^{3}$ fatigue cycles, while $\mathrm{VO}_{2}$ single layer samples almost become invalid (see Figs. 8c, d).

\subsection{Core-shell structures}

Unlike $\mathrm{VO}_{2}$ films prepared PVD methods, thermochromic coatings based on $\mathrm{VO}_{2}$ nanoparticles have different surface morphologies and larger specific area. Therefore, protective layers may not be suitable for $\mathrm{VO}_{2}$ nanoparticles. Core-shell structures for $\mathrm{VO}_{2}$ nanoparticles have been demonstrated to be an effective way to improve performances of the $\mathrm{VO}_{2}$ core by using selected materials as shells [29, 55, 91-93].

Silica $\left(\mathrm{SiO}_{2}\right)$ is the most studied material utilized as shell to improve the durability of $\mathrm{VO}_{2}$ nanoparticles $[29,55,94,95]$. Firstly, the $\mathrm{SiO}_{2}$ layer is optically transparent and chemically stable. Secondly, the utilization of $\mathrm{SiO}_{2}$ layer can prevent nanoparticles from agglomeration [95]. Thirdly, the $\mathrm{SiO}_{2}$ layer is helpful to improve the chemical stability and mechanical stability of $\mathrm{VO}_{2}$ nanoparticles. Gao et al. [29] synthesized $\mathrm{VO}_{2} @ \mathrm{SiO}_{2}$ core- 


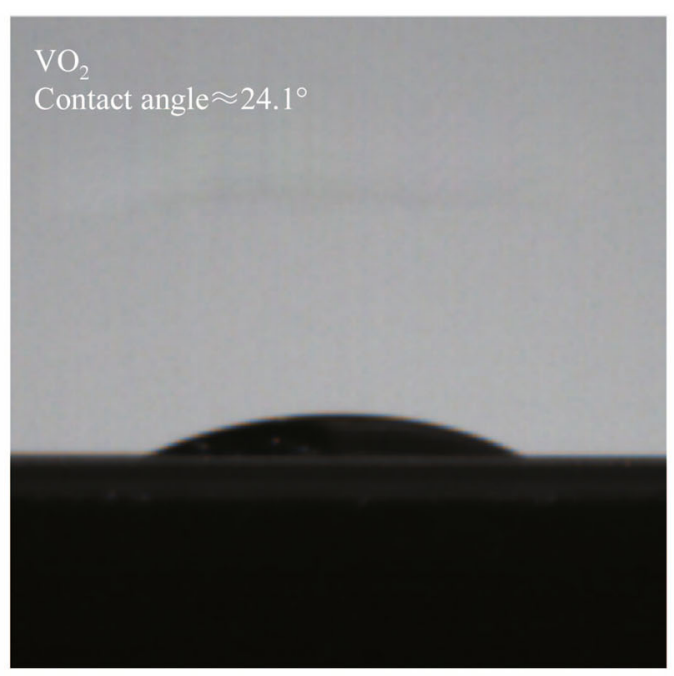

(a)

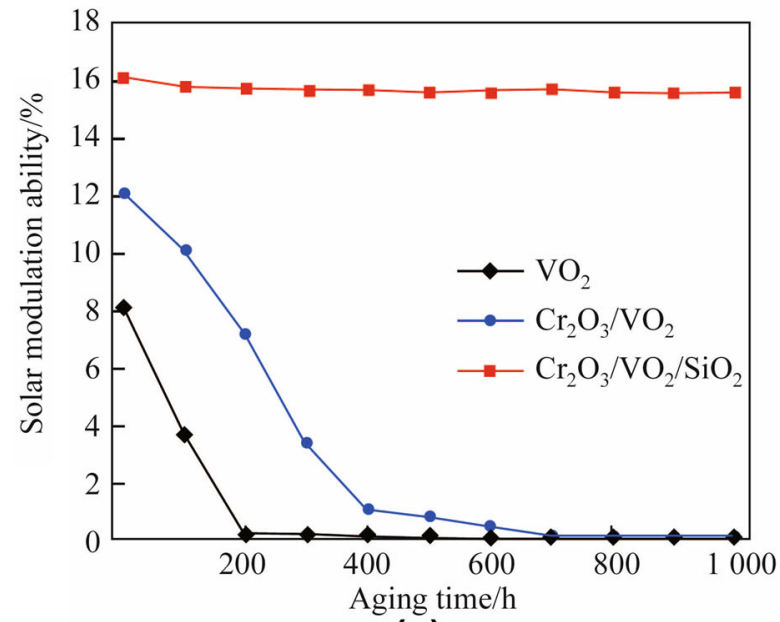

(c)

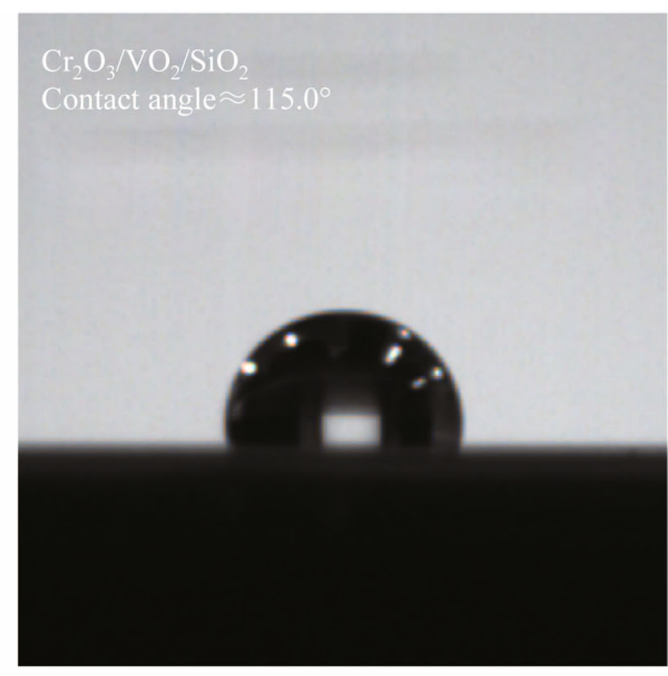

(b)

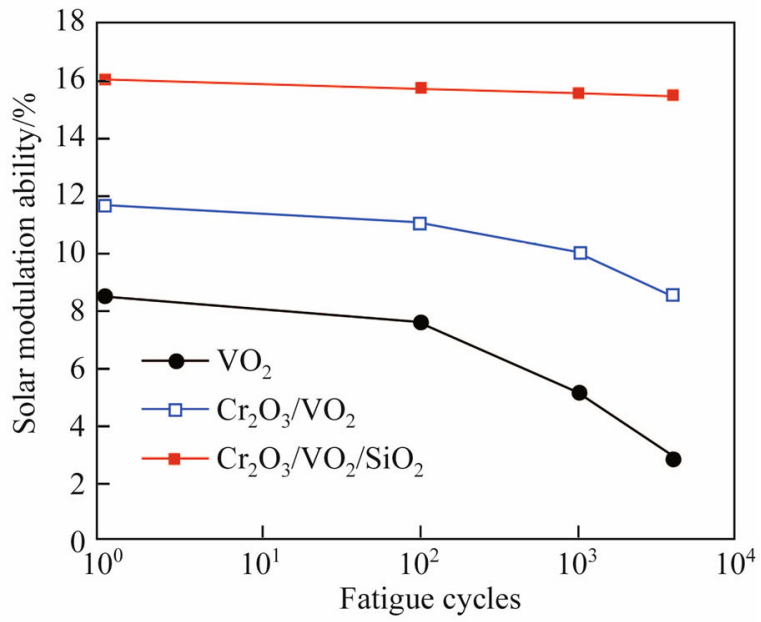

(d)

Fig. 8 Images of contact angle measurement of a the single layer $\mathrm{VO}_{2}$ and $\mathbf{b}$ the proposed $\mathrm{Cr}_{2} \mathrm{O}_{3} / \mathrm{VO}_{2} / \mathrm{SiO}_{2}$ structure. Variation curves of $\Delta T_{\text {sol }}$ for $\mathrm{VO}_{2}, \mathrm{Cr}_{2} \mathrm{O}_{3} / \mathrm{VO}_{2}$ and $\mathrm{Cr}_{2} \mathrm{O}_{3} / \mathrm{VO}_{2} / \mathrm{SiO}_{2}$ with different duration time $\mathbf{c}$ and different fatigue cycles $\mathbf{d}$ [30]

shell structure via solution method with PVP pretreatment. The proposed $\mathrm{VO}_{2} @ \mathrm{SiO}_{2}$ structures can effectively enhance the anti-oxidation and acid-resisting properties of $\mathrm{VO}_{2}$. After annealing at $300{ }^{\circ} \mathrm{C}$ in air for $2 \mathrm{~h}$, most $\mathrm{VO}_{2}$ nanoparticles without $\mathrm{SiO}_{2}$ shell have transformed into $\mathrm{V}_{2} \mathrm{O}_{5}$, while no trace of $\mathrm{V}_{2} \mathrm{O}_{5}$ can be observed in the $\mathrm{VO}_{2} @ \mathrm{SiO}_{2}$ sample. The acid-corrosion experiment of the samples in a hydrochloric acid solution $(\mathrm{pH}=1)$ also confirmed the chemical stability of $\mathrm{VO}_{2} @ \mathrm{SiO}_{2}$.

$\mathrm{Al}$ oxide is a promoted material as the shell to protect nanoparticles from corrosion, which has been demonstrated to protect perovskite solar cells from corrosion [96]. $\mathrm{VO}_{2} /$ Al-O core-shell structures have been fabricated, where different duration tests have been carried out [97]. For the uncoated sample, the $\mathrm{VO}_{2}$ nanoparticles were oxidized into $\mathrm{V}_{2} \mathrm{O}_{5}$ when heated at $300{ }^{\circ} \mathrm{C}$, while the coated $\mathrm{VO}_{2} / \mathrm{Al}-\mathrm{O}$ remains stable even heated up to $350{ }^{\circ} \mathrm{C}$. While treated in the damp heating environment, the uncoated sample loses thermochromic properties only after $48 \mathrm{~h}$, while the $\mathrm{VO}_{2}$ nanoparticles coated with $\mathrm{Al}-\mathrm{O}$ shell remains stable even after 20 days.

In the study by Chen et al. [43], $\mathrm{ZnO}$ was selected as the shell to prevent $\mathrm{VO}_{2}$ nanoparticles from being oxidized. From the TEM images of $\mathrm{VO}_{2} @ \mathrm{ZnO}$ shown in Figs. 9a, b, it can be observed that $\mathrm{VO}_{2}$ nanoparticles were closely surrounded by $\mathrm{ZnO}$ shells. Compared with uncoated $\mathrm{VO}_{2}$ film, $\mathrm{ZnO}$ coating $\mathrm{VO}_{2}$ films show greater effects on the properties (see Fig. 9c). The $\Delta T_{\text {sol }}$ and $T_{\text {lum }}$ are improved from $38.9 \%$ and $17.2 \%$ to $51.0 \%$ and $19.1 \%$ (see Fig. 9d). An extreme environment for a constant temperature of $60{ }^{\circ} \mathrm{C}$ and humidity of $90 \%$ which will accelerate samples losing the thermochromic performance in this condition of the environment and evaluated relative durability. For the uncoated $\mathrm{VO}_{2}$ film, the thermochromism vanishes 


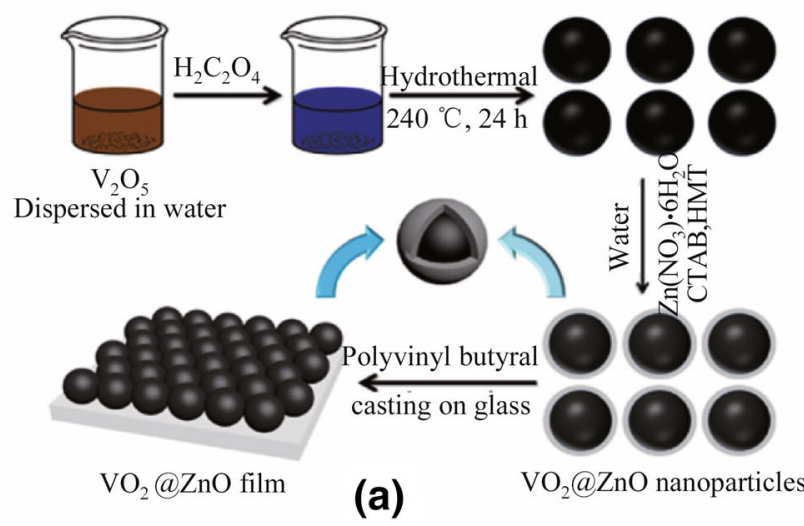

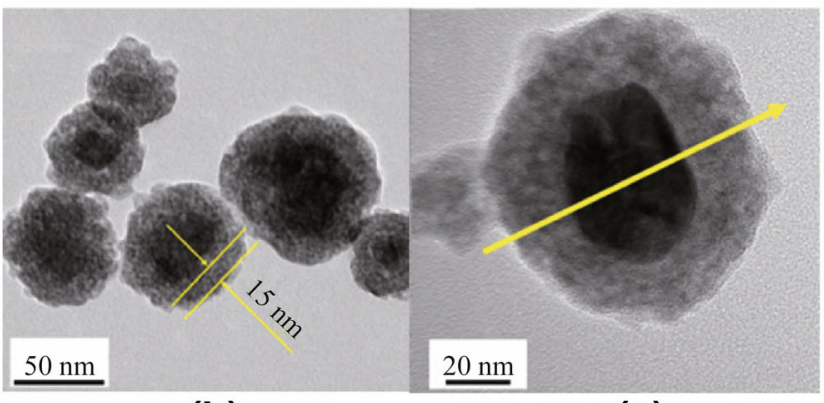

(b) (c)

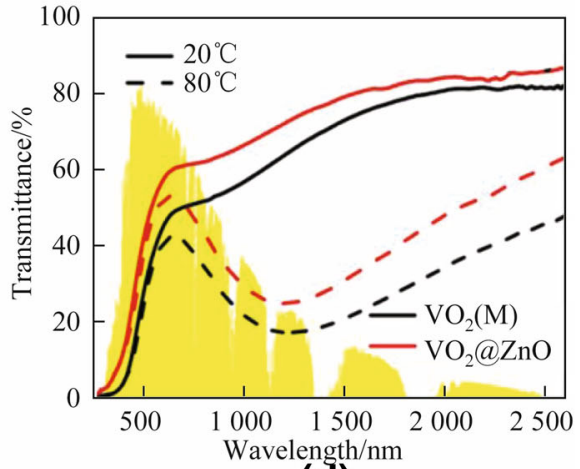

(d)

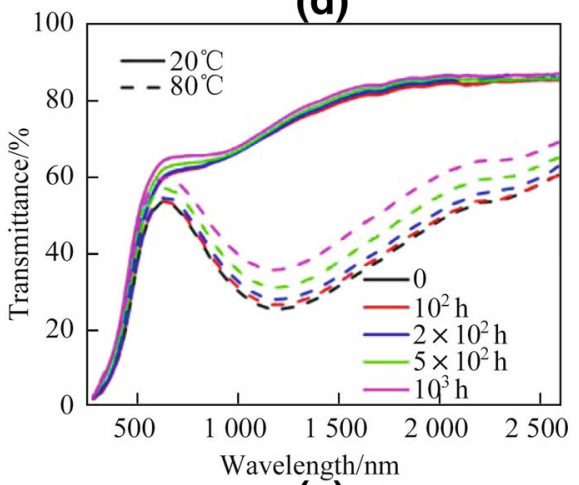

(e)

Fig. 9 a Experimental flow chart for the synthesis of $\mathrm{VO}_{2} @ \mathrm{ZnO}$ core-shell structure nanoparticles and $\mathrm{VO}_{2} @ \mathrm{ZnO}$ film, b-c TEM images of $\mathrm{VO}_{2} @ \mathrm{ZnO}$ core-shell structure nanoparticle, $\mathbf{d}$ optical transmittance spectra at $20^{\circ} \mathrm{C}$ and $80{ }^{\circ} \mathrm{C}$ of uncoated $\mathrm{VO}_{2}$ film and $\mathrm{VO}_{2} @ \mathrm{ZnO}$ film, e optical transmittance spectra of $\mathrm{VO}_{2} @ \mathrm{ZnO}$ in a constant temperature $\left(60{ }^{\circ} \mathrm{C}\right)$ and humidity $(90 \%)[43]$

completely after $30 \mathrm{~h}$ treatment. Compared with the uncoated $\mathrm{VO}_{2}$, the $\mathrm{VO}_{2} @ \mathrm{ZnO}$ shows striking durability. The transmittance curve at different temperatures of $\mathrm{VO}_{2} @ \mathrm{ZnO}$ film remains almost intact after $10^{3} \mathrm{~h}$ testing, which means that it still has good thermochromic performance (see Fig. 9e).

\section{Multifunctional design and construction}

Nowadays, multifunctional fenestrations of the buildings are favored by customers. As is known to all, the fenestrations of the buildings and vehicles always need to be cleaned, which would lead to additional pollutants from the use of detergents and wasting a mass of labors. Semiconductor photocatalysts like $\mathrm{TiO}_{2}$ are widely and frequently employed to decompose pollutants. There are three different polymorphs of crystalline $\mathrm{TiO}_{2}$ : rutile(tetragonal), anatase (tetragonal) and brookite (orthorhombic). Rutile $\mathrm{TiO}_{2}\left(\mathrm{TiO}_{2}(\mathrm{R})\right)$ is a thermodynamically stable phase at all temperatures and the most common natural form of $\mathrm{TiO}_{2}$. Due to similar lattice parameters, $\mathrm{TiO}_{2}(\mathrm{R})$ films are acted as buffer layer and growth template of $\mathrm{VO}_{2}$ (M) films. Nevertheless, $\mathrm{TiO}_{2}$ (R) films are less efficient photocatalysts than anatase $\mathrm{TiO}_{2}\left(\mathrm{TiO}_{2}(\mathrm{~A})\right)$ films, which occupy an important position in the studies of photocatalytic active. Zheng et al. [11] constructed a $\mathrm{TiO}_{2}(\mathrm{R}) / \mathrm{VO}_{2}(\mathrm{M}) / \mathrm{TiO}_{2}$ (A) multilayer film, while the photocatalytic and photoinduced hydrophilic properties from the top $\mathrm{TiO}_{2}(\mathrm{~A})$ layer for self-cleaning effects (see Fig. 10a).

Self-cleaning property of the $\mathrm{TiO}_{2}(\mathrm{R}) / \mathrm{VO}_{2}(\mathrm{M}) / \mathrm{TiO}_{2}$ (A) multilayer film was evaluated by the decomposition of stearic acid under UV radiation. The degradation of stearic acid was related to the decrease in IR absorption of the $\mathrm{C}-\mathrm{H}$ stretches, which has been summarized in Fig. 10b. Before UV light irradiation, the characteristic alkyl $\mathrm{C}-\mathrm{H}$ bond stretching vibrations of $\mathrm{CH}_{2}$ and $\mathrm{CH}_{3}$ groups (3 000-2 $800 \mathrm{~cm}^{-1}$ ) can be distinctly detected. After UV light irradiation of $20 \mathrm{~min}$, the absorbance of $\mathrm{C}-\mathrm{H}$ bond stretching vibrations decreased drastically, which meant that a considerable proportion of stearic acid was decomposed. The IR absorbance slowly became weak with the increase of irradiation time, and finally almost faded away after $180 \mathrm{~min}$ irradiation time. In addition, the degradation of stearic acid also can be confirmed by the changes of the contact angle of the multilayer film. The contact angles of the surface transform from $99.5^{\circ}$ (hydrophobic) to $11.5^{\circ}$ (hydrophilic) (see Fig. 10c), which can be ascribed to the degradation of stearic acid and the photoinduced hydrophilicity of multilayer film. The photocatalytic activity of $\mathrm{TiO}_{2}(\mathrm{R}) / \mathrm{VO}_{2}(\mathrm{M}) /$ 


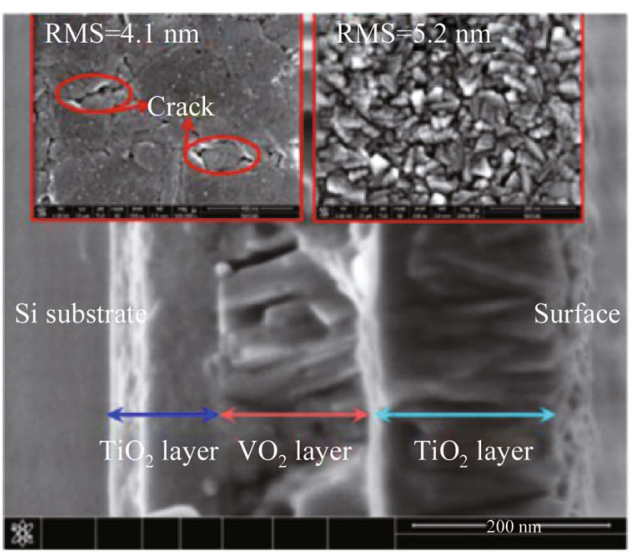

(a)

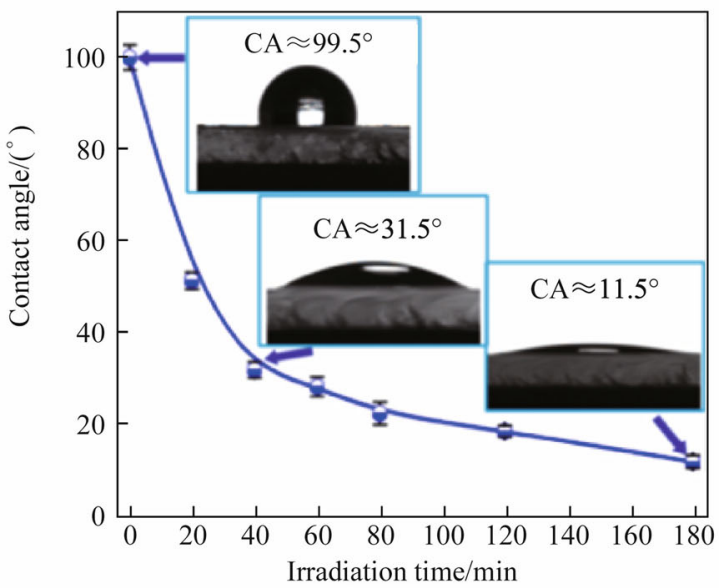

(c)

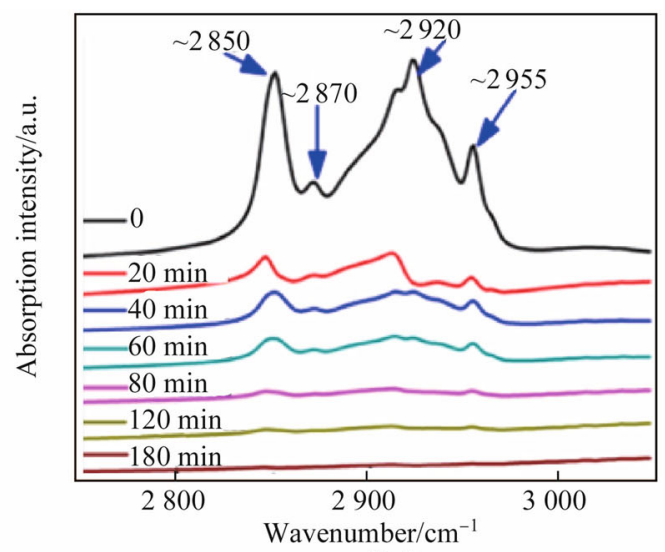

(b)

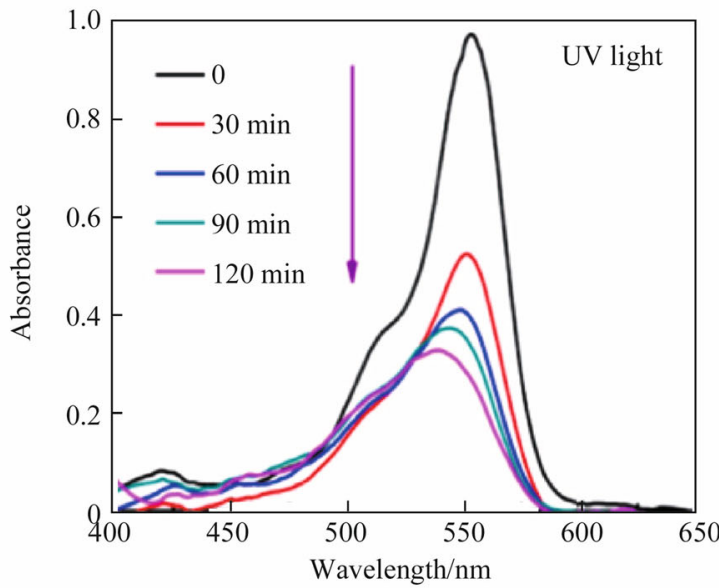

(d)

Fig. 10 a FESEM image of a fractured cross-section of the multilayer film (the insets are surface morphology of $\mathrm{VO}_{2}(\mathrm{M})$ (left) and $\mathrm{TiO}_{2}$ (A) layers (right), respectively), b IR absorbance spectra of $\mathrm{TiO}_{2}(\mathrm{R}) / \mathrm{VO}_{2}(\mathrm{M}) / \mathrm{TiO}_{2}(\mathrm{~A})$ multilayer film with stearic acid overlayer at various irradiation time under UV light, $\mathbf{c}$ CAs of the multilayer film with stearic acid overlayer dependence on irradiation time (the insets are corresponding water droplet shapes on the surface), $\mathbf{d}$ variation of absorption spectra of RhB aqueous solution degraded by the multilayer film [11]

$\mathrm{TiO}_{2}$ (A) multilayer film also has been demonstrated by the decomposition rate of RhB under UV light irradiation. Figure $10 \mathrm{~d}$ shows that the absorption spectra of $\mathrm{RhB}$ aqueous solution degraded by the multilayer film under UV light irradiation. Thermochromic smart coatings with self-cleaning function have also been achieved by the $\mathrm{VO}_{2} / \mathrm{SiO}_{2} / \mathrm{TiO}_{2}$ structure where the $\mathrm{SiO}_{2}$ layer act as the ion-barrier interlayer [66]. The proposed VST structure shows a significant degradation rate of stearic acid and is comparable to that of a standard Pilkington Activ glass, which is a commercially available self-cleaning glass that contains a thin $\mathrm{TiO}_{2}$ layer $(15 \mathrm{~nm})$ deposited by CVD methods.

For self-cleaning function and improved stability, $\mathrm{VO}_{2}$ thermochromic smart coatings with hydrophobic surface have been favored and studied by researchers. $\mathrm{VO}_{2}$ films with moth-eye nanostructures have been fabricated to enhance the thermochromic properties and the hydrophobic surface (contact angle $120^{\circ}$ ) can be achieved with additional overcoat [98]. Fused silica substrates with AR patterns of different periods $(0,210,440,580$ and $1000 \mathrm{~nm}$ ) were prepared by reactive ion etching using $2 \mathrm{D}$ polystyrene colloidal crystals as a mask. A nipple arrays based on $\mathrm{VO}_{2} / \mathrm{SiO}_{2}$ have been realized and the additional fluorooctyltriethoxysilane (FOS) overcoat provides hydrophobicity of the surface (see Fig. 11).

The biosafety of $\mathrm{VO}_{2}$ is also under consideration, while the $\mathrm{ZnO}$ layer has been used to provide the antibacterial property [99]. $\mathrm{ZnO}$ coated $\mathrm{VO}_{2}$ thin films exhibited excellent antibacterial property proved by SEM observation results that $\mathrm{ZnO}$ coated samples cause the membrane disruption and cytoplasm leakage of $E$. coli cells and fluorescence staining results that the amounts of viable bacteria are evidently lower on the surface of $\mathrm{ZnO}$ coated films than that of uncoated films (see Fig. 12). The sterilization mechanism of $\mathrm{ZnO}$ films is believed to be attributed to the synergistic effect of released zinc ions and $\mathrm{ZnO}$ 


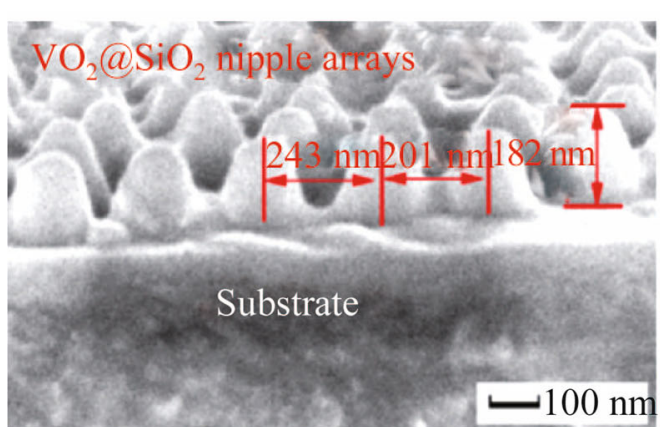

(a)

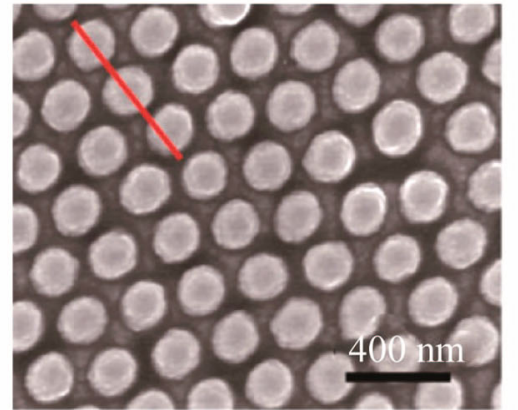

(b)

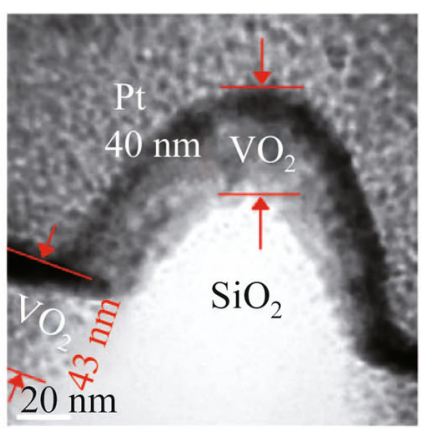

(c)

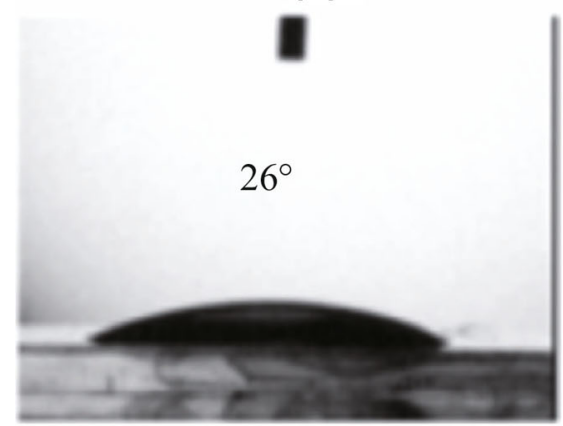

(d)

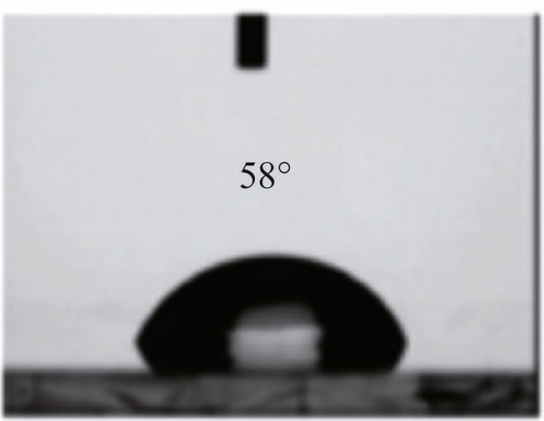

(e)

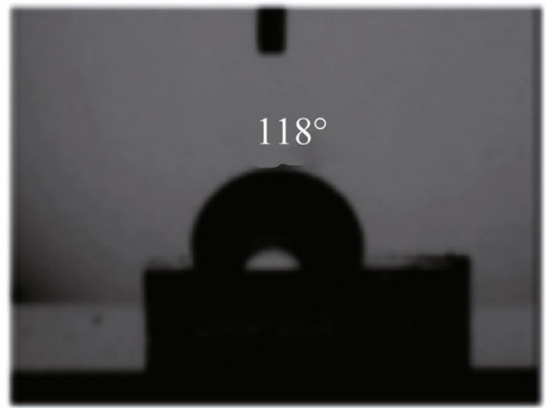

(f)

Fig. 11 a SEM cross-sectional profile of the sample with $210 \mathrm{~nm}$ period, b top-view SEM image of the sample with $440 \mathrm{~nm}$ period, $\mathbf{c}$ TEM cross-sectional image to show the thickness of $\mathrm{VO}_{2}$ coatings on $\mathrm{SiO}_{2}$, d planar $\mathrm{VO}_{2}, 210 \mathrm{~nm}$ patterned $\mathrm{VO}_{2}$ with $40 \mathrm{~nm}$ thickness, and $210 \mathrm{~nm}$ patterned $\mathrm{VO}_{2}$ with FOS overcoat [98]

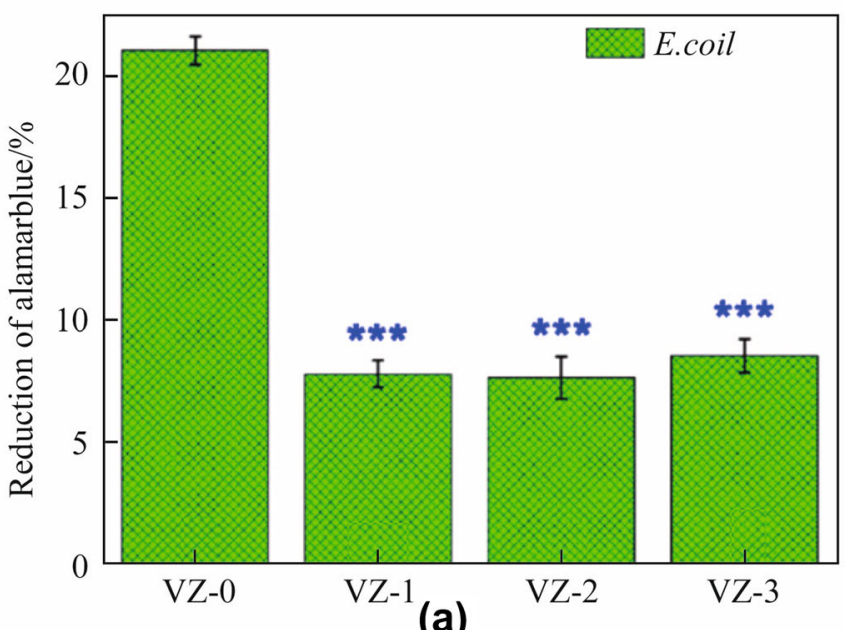

(a)

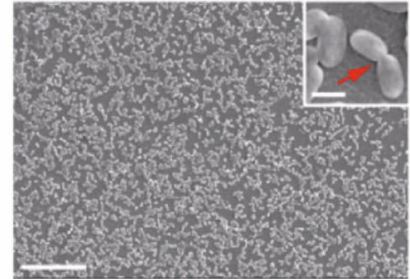

(b)

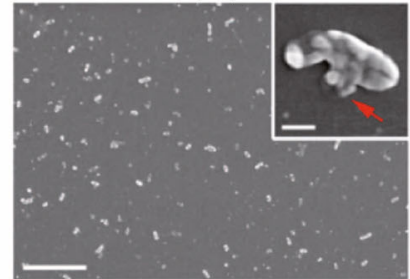

(d)

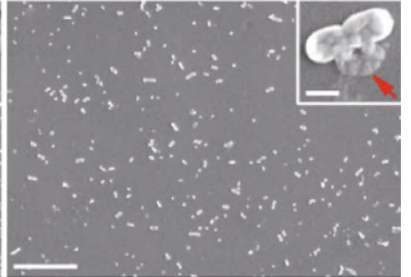

(c)

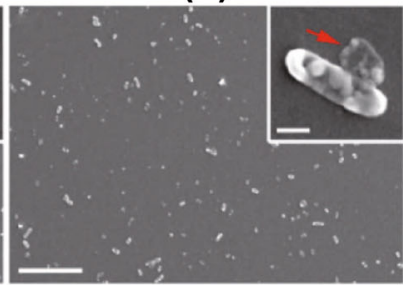

(e)

Fig. 12 a Proliferation viability of E. coli after culture of $24 \mathrm{~h}$ on samples VZ-0, VZ-1, VZ-2 and VZ-3, accompanied by the SEM morphology of $E$. coli after culture of $24 \mathrm{~h}$ on surfaces of $\mathbf{b}$ VZ-0, $\mathbf{c}$ VZ-1, d VZ-2 and e VZ-3 (the scale bar is $20 \mu \mathrm{m}$. The insets show the corresponding partially enlarged SEM images and the scale bar is $1 \mu \mathrm{m})$ [99]

nanoparticles by elaborately designing a verification experiment. More importantly, the $\mathrm{ZnO}$ layer with an appropriate thickness can significantly reduce the cytotoxicity of $\mathrm{VO}_{2}$ and thus promote the $\mathrm{VO}_{2}$ biosafety.

\section{Large-scale production of $\mathrm{VO}_{2}$ smart coatings}

For commercial applications on building fenestrations in our daily life, large-scale production of $\mathrm{VO}_{2}$ based smart coatings is a great challenge that must be developed. For $\mathrm{VO}_{2}$ based films, magnetron sputtering is the most 
commonly used method and several works about largescale production of $\mathrm{VO}_{2}$ based films by magnetron sputtering have been reported. A large-scale $\mathrm{TiO}_{2}(\mathrm{R}) / \mathrm{VO}_{2}(\mathrm{M}) /$ $\mathrm{TiO}_{2}$ (A) multilayer film was prepared on a glass with the area of $400 \mathrm{~mm} \times 400 \mathrm{~mm}$ using magnetron sputtering method by Zheng et al. [11], where a combination of energy-saving, antifogging and self-cleaning functions has been achieved (see Fig. 13a). $\mathrm{TiO}_{2}(\mathrm{R}) / \mathrm{VO}_{2}(\mathrm{M}) / \mathrm{TiO}_{2}$ (A) multilayer film was deposited using medium frequency reactive magnetron sputtering (MFRMS, see Fig. 13b) system to sputter planar rectangular metal targets in a suitable atmosphere. The proposed structure shows excellent ability to block out infrared irradiation, which causes a temperature reduction of $12{ }^{\circ} \mathrm{C}$ compared with the blank glass (see Fig. 13c).

The magnetron sputtering coating system could be applied in architecture commercial glasses and the designed large area sputtering cathode can make the coating on large area glass substrates. The optimized design and precise manufacturing can guarantee to get a higher vacuum and a shorter cycle time by using a smaller pumping system. Sputtering is a vacuum process used to deposit thin films on substrates. It is performed by applying a high voltage across a low-pressure gas (usually argon) to create a "plasma", which consists of electrons and gas ions in a high-energy state. During sputtering, energized plasma ions strike the target, which is composed of the desired coating material, and caused atoms from that target to be ejected with enough energy to travel to and bond with the substrate (see Fig. 13d).

In terms of $\mathrm{VO}_{2}$ nanoparticles, which are usually synthesized by solution methods, the first requirement for commercial application is the preparation of $\mathrm{VO}_{2}$ nanoparticles with uniform particle sizes. Then, $\mathrm{VO}_{2}$ nanoparticles would be dissolved in suitable resins and coated on substrates such as glasses and PET. Calculations based on effective medium theory made by $\mathrm{Li}$ et al. [80] shows that dilute composites with $\mathrm{VO}_{2}$ nanoparticles embedded in hosts with properties mimicking glass or polymer can yield significantly decreased luminous absorption jointly with much enhanced transmittance modulation of solar energy. These results demonstrate that $\mathrm{VO}_{2}$-based nanothermochromics open new avenues toward energy-efficient fenestration. Polymer hosts such as

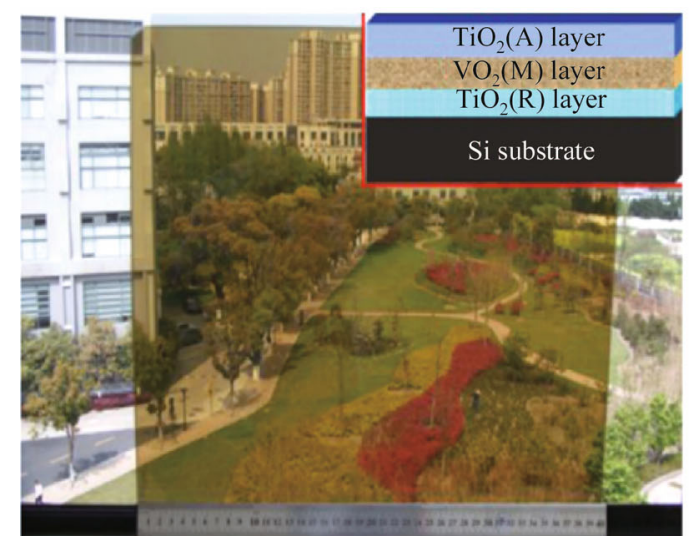

(a)

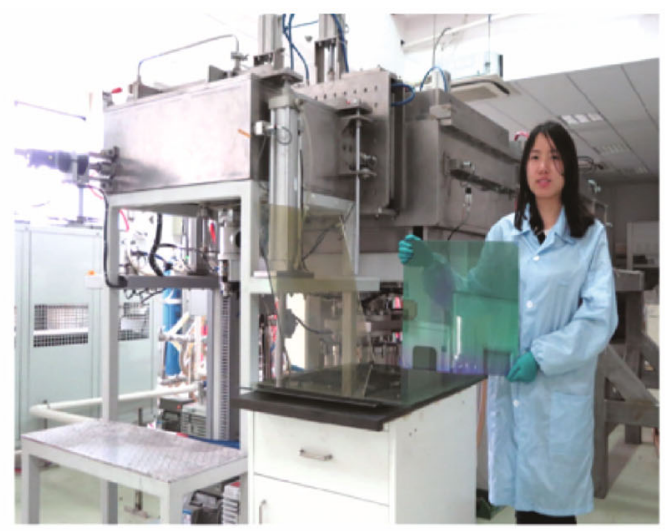

(b)

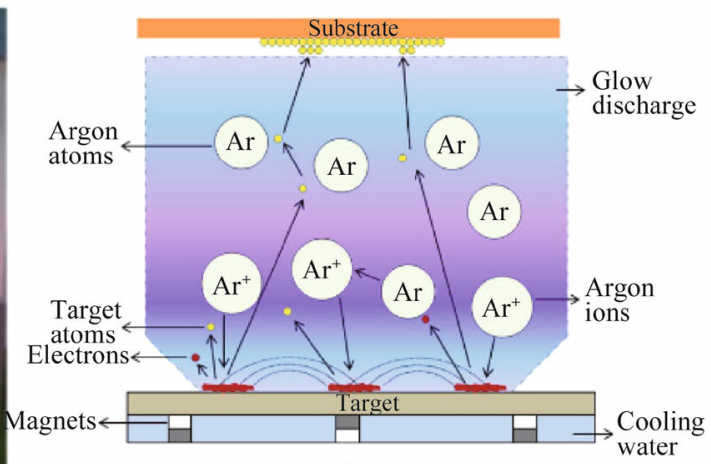

(d)

Fig. 13 a Photograph of large-scale $(400 \mathrm{~mm} \times 400 \mathrm{~mm}$ ) multilayer film at room temperature (the inset is corresponding structure diagram of the multilayer film), b photograph of the magnetron sputtering system, $\mathbf{c}$ photographic illustration of the testing system, 1: temperature monitor, 2: temperature probe, 3: infrared lamps, 4: blank glass, 5: glass with $\mathrm{TiO}_{2}(\mathrm{R}) / \mathrm{VO}_{2}(\mathrm{M}) / \mathrm{TiO}_{2}(\mathrm{~A})$ multilayer film, d schematic diagram illustrating the basic components of a magnetron sputtering system $[11,100]$ 
polyurethane (PU), poly(vinylpyrrolidone) (PVP) and polyamide (PA) have been used. Surface modulation of $\mathrm{VO}_{2}$ nanoparticles will be carried out and the treated nanoparticles will be dispersed in the polymer hosts to form the suspension. The $\mathrm{VO}_{2}$ based coatings are prepared by casting the suspension on the substrates. Preparation procedure for $\mathrm{VO}_{2} @ \mathrm{SiO}_{2}$ nanoparticles and flexible composite films has been shown in Fig. 14a [29]. Thermal stable PET film covered with $\mathrm{VO}_{2}$ has been stuck on the glass on which has a size of $1.65 \mathrm{~m} \times 1.65 \mathrm{~m}$ of a model house (see Fig. 14b) [101-104]. The demonstration of the $\mathrm{VO}_{2}$ glazing's application indicated that compared with the use of the ordinary glazing, the use of $\mathrm{VO}_{2}$ glazing could save $10.2 \%-19.9 \%$ cumulative cooling load (see Fig. 14c).

\section{Conclusions and prospects}

As the most attractive thermochromic technology, $\mathrm{VO}_{2}$ based smart coatings have gained great attention by researchers and many efforts have been made to promote the real commercialization. Methods such as multilayer stacks, composite films, core-shell structures have been carried out to improve thermochromic performance with enhanced luminous transmittance, solar modulation ability and environmental stability. However, more efforts are still needed to make this technology into our daily lives.

(i) Optical performances of $\mathrm{VO}_{2}$ thermochromic smart coatings can be improved by methods, such as element doping, fabricating multilayer

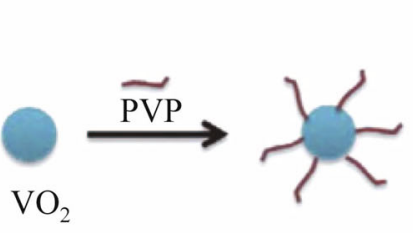

Step 1: PVP pretreatment

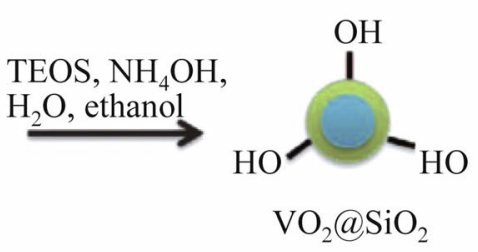

Step 2: shell growth

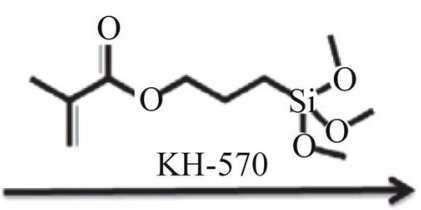

Step 3: surface modification

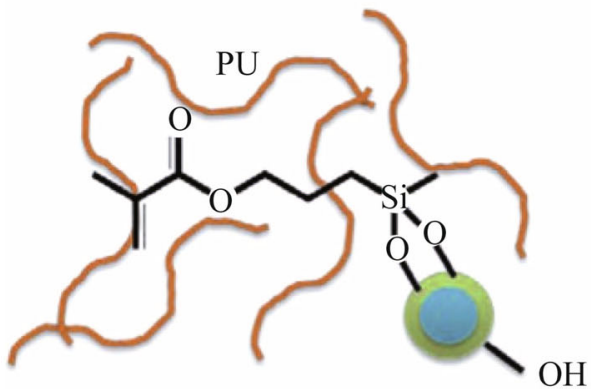

Step 4: dispersion in PU

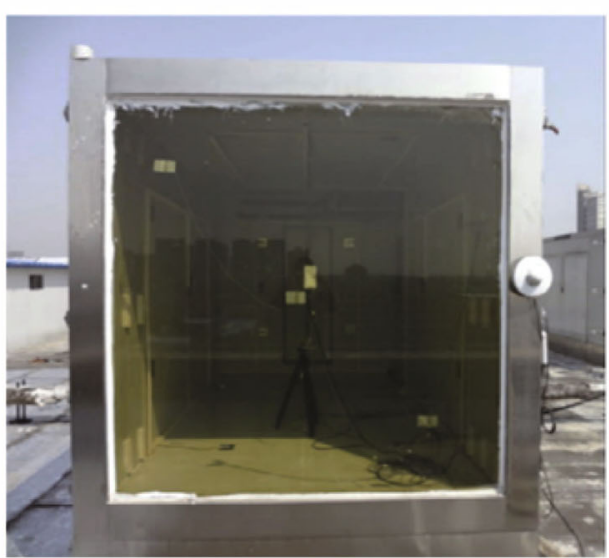

(b)

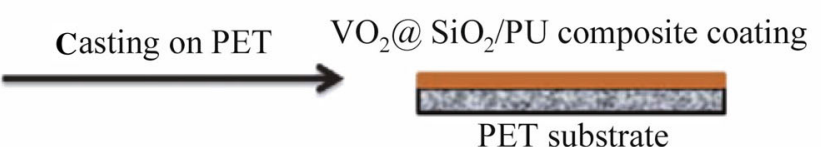

(a)

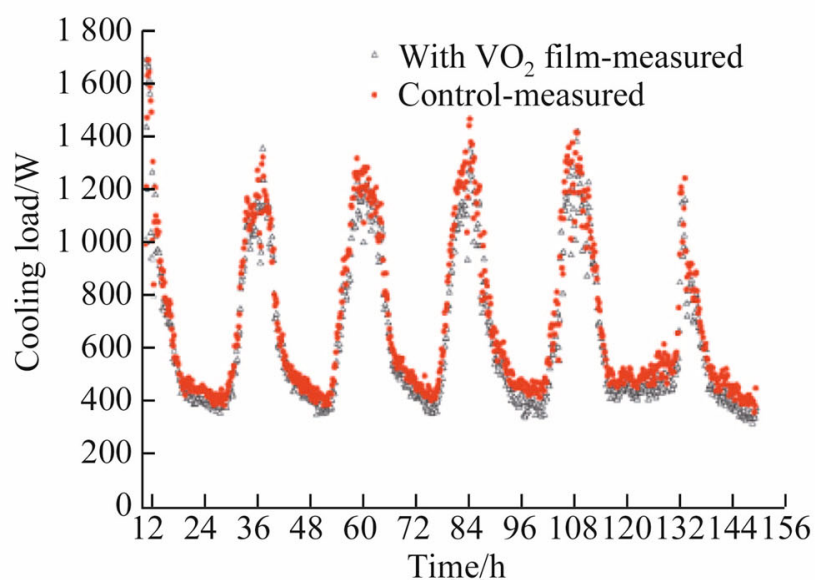

(c)

Fig. 14 a Preparation procedure for $\mathrm{VO}_{2} @ \mathrm{SiO}_{2}$ nanoparticles and flexible composite films, b photograph of a model room with $\mathrm{VO}_{2}$ glazing $(1.65 \mathrm{~m} \times 1.65 \mathrm{~m})$, c cooling load comparison during the demonstration of $\mathrm{VO}_{2}$ glazing $[29,101]$ 
structures, and designing nanostructures. For practical applications, $\mathrm{VO}_{2}$ smart coatings should have $50 \%$ luminous transmittance and $15 \%$ solar modulation ability for sufficient energy-saving effect. Optical properties of $\mathrm{VO}_{2}$ smart coatings can be further improved by computational calculations and simulations for better luminous transmittance and solar modulation ability.

(ii) Environmental stability of $\mathrm{VO}_{2}$ coatings is a great challenge for long-time use. Protective layers for $\mathrm{VO}_{2}$ films as well as core-shell structures for $\mathrm{VO}_{2}$ nanoparticles can effectively improve the environmental stability of $\mathrm{VO}_{2}$ coatings. Future work can be carried out by choosing materials with versatility for protective, antireflection and selfcleaning functions.

(iii) Large-scale production of $\mathrm{VO}_{2}$ smart coatings is necessary to turn this technology from the lab into the industrial and commercial application. Traditional methods, such as hydrothermal synthesis, spray pyrolysis and sol-gel, etc., are limited due to their low production and complicated process. An effective way to solve this problem is fabricating $\mathrm{VO}_{2}$ based smart coatings during the production of glasses, just like the deposition of lowemissivity (low-E) coatings on the glass production lines.

Acknowledgements This study was financially supported by the National Natural Science Foundation of China (Grant No. 51572284) and the "Youth Innovation Promotion Association, Chinese Academy of Sciences".

Open Access This article is distributed under the terms of the Creative Commons Attribution 4.0 International License (http://crea tivecommons.org/licenses/by/4.0/), which permits unrestricted use, distribution, and reproduction in any medium, provided you give appropriate credit to the original author(s) and the source, provide a link to the Creative Commons license, and indicate if changes were made.

\section{References}

1. Omer AM (2008) Energy, environment and sustainable development. Renew Sustain Energy Rev 12:2265-2300

2. Granqvist CG, Lansåker PC, Mlyuka NR et al (2009) Progress in chromogenics: new results for electrochromic and thermochromic materials and devices. Solar Energy Mater Solar Cells 93(12):2032-2039

3. Granqvist CG (2016) Electrochromics and thermochromics: towards a new paradigm for energy efficient buildings. Mater Today Proc 3:S2-S11

4. Granqvist CG (2016) Recent progress in thermochromics and electrochromics: a brief survey. Thin Solid Films 614:90-96
5. Granqvist CG, Green S, Niklasson GA et al (2010) Advances in chromogenic materials and devices. Thin Solid Films 518(11):3046-3053

6. Granqvist CG, Pehlivan IB, Ji YX et al (2014) Electrochromics and thermochromics for energy efficient fenestration: functionalities based on nanoparticles of $\mathrm{In}_{2} \mathrm{O}_{3}: \mathrm{Sn}$ and $\mathrm{VO}_{2}$. Thin Solid Films 559:2-8

7. Deb SK (2008) Opportunities and challenges in science and technology of $\mathrm{WO}_{3}$ for electrochromic and related applications. Solar Energy Mater Solar Cells 92(2):245-258

8. Granqvist CG (2014) Oxide-based chromogenic coatings and devices for energy efficient fenestration: brief survey and update on thermochromics and electrochromics. J Vac Sci Technol B 32(6):060801

9. Wang J, Zhang L, Yu L et al (2014) A bi-functional device for self-powered electrochromic window and self-rechargeable transparent battery applications. Nat Commun 5(4921):1-7

10. Granqvist CG (2012) Oxide electrochromics: an introduction to devices and materials. Solar Energy Mater Solar Cells 99:1-13

11. Zheng J, Bao S, Jin $\mathrm{P}(2015) \mathrm{TiO}_{2}(\mathrm{R}) / \mathrm{VO}_{2}(\mathrm{M}) / \mathrm{TiO}{ }_{2}(\mathrm{~A})$ multilayer film as smart window: combination of energy-saving, antifogging and self-cleaning functions. Nano Energy $11: 136-145$

12. Chang T, Cao X, Li N et al (2017) Facile and low-temperature fabrication of thermochromic $\mathrm{Cr}_{2} \mathrm{O}_{3} / \mathrm{VO}_{2}$ smart coatings: enhanced solar modulation ability, high luminous transmittance and UV-shielding function. ACS Appl Mater Interfaces 9(31):26029-26037

13. Babulanam SM, Eriksson TS, Niklasson GA et al (1987) Thermochromic $\mathrm{VO}_{2}$ films for energy-efficient windows. Solar Energy Mater 16(5):347-363

14. Sobhan MA, Kivaisi RT, Stjerna B et al (1996) Thermochromism of sputter deposited $\mathrm{W}_{x} \mathrm{~V}_{1-x} \mathrm{O}_{2}$ films. Solar Energy Mater Solar Cells 44(4):451-455

15. Shen N, Li Y, Yi XJ (2006) Preparation of $\mathrm{VO}_{2}$ films with nanostructure and improvement on its visible transmittance. J Infrared Millim Waves 25(3):199-202

16. Soltani M, Chaker M, Haddad E et al (2006) Thermochromic vanadium dioxide smart coatings grown on Kapton substrates by reactive pulsed laser deposition. J Vac Sci Technol A Vac Surf Films 24(3):612-617

17. Binions R, Hyett G, Piccirillo C et al (2007) Doped and undoped vanadium dioxide thin films prepared by atmospheric pressure chemical vapour deposition from vanadyl acetylacetonate and tungsten hexachloride: the effects of thickness and crystallographic orientation on thermochromic properties. J Mater Chem 17(44):4652-4660

18. Evans P, Pemble ME, Sheel DW et al (2007) Multi-functional self-cleaning thermochromic films by atmospheric pressure chemical vapour deposition. J Photochem Photobiol A Chem 189(2-3):387-397

19. Shi JQ, Zhou SX, You B et al (2007) Preparation and thermochromic property of tungsten-doped vanadium dioxide particles. Solar Energy Mater Solar Cells 91(19):1856-1862

20. La M, Zhou H, Li N et al (2017) Improved performance of Mg$\mathrm{Y}$ alloy thin film switchable mirrors after coating with a superhydrophobic surface. Appl Surf Sci 403:23-28

21. Jang WL, Lu YM, Chen CL et al (2014) Local geometric and electronic structures of gasochromic $\mathrm{VO}_{(x)}$ films. Phys Chem Chem Phys 16(10):4699-4708

22. Wittwer V, Datz M, Ell J et al (2004) Gasochromic windows. Solar Energy Mater Solar Cells 84(1-4):305-314

23. Li N, Li Y, Sun G et al (2017) Selective and tunable near-infrared and visible light transmittance of $\mathrm{MoO}_{3-x}$ nanocomposites with different crystallinity. Chem Asian J 12(14):1709-1714 
24. Li N, Li Y, Li W et al (2016) One-step hydrothermal synthesis of $\mathrm{TiO}_{2} @ \mathrm{MoO}_{3}$ core-shell nanomaterial: microstructure, growth mechanism, and improved photochromic property. J Phys Chem C 120(6):3341-3349

25. Li N, Li Y, Zhou Y et al (2017) Interfacial-charge-transferinduced photochromism of $\mathrm{MoO}_{3} @ \mathrm{TiO}_{2}$ crystalline-core amorphous-shell nanorods. Solar Energy Mater Solar Cells 160:116-125

26. Li N, Li Y, Sun G et al (2017) Enhanced photochromic modulation efficiency: a novel plasmonic molybdenum oxide hybrid. Nanoscale 9(24):8298-8304

27. Morin FJ (1959) Oxides which show a metal-to-insulator transition at the Neel temperature. Phys Rev Lett 3(1):34-36

28. Zhang Z, Gao Y, Luo H et al (2011) Solution-based fabrication of vanadium dioxide on $\mathrm{F}: \mathrm{SnO}_{2}$ substrates with largely enhanced thermochromism and low-emissivity for energy-saving applications. Energy Environ Sci 4(10):4290-4297

29. Gao Y, Wang S, Luo H et al (2012) Enhanced chemical stability of $\mathrm{VO}_{2}$ nanoparticles by the formation of $\mathrm{SiO}_{2} / \mathrm{VO}_{2}$ core/shell structures and the application to transparent and flexible $\mathrm{VO}_{2-}$ based composite foils with excellent thermochromic properties for solar heat control. Energy Environ Sci 5(3):6104-6110

30. Chang T, Cao X, Dedon LR et al (2018) Optical design and stability study for ultrahigh-performance and long-lived vanadium dioxide-based thermochromic coatings. Nano Energy 44:256-264

31. Gao Y, Wang S, Kang L et al (2012) $\mathrm{VO}_{2}-\mathrm{Sb}: \mathrm{SnO}_{2}$ composite thermochromic smart glass foil. Energy Environ Sci $5(8): 8234-8237$

32. Gao Y, Luo H, Zhang Z et al (2012) Nanoceramic $\mathrm{VO}_{2}$ thermochromic smart glass: a review on progress in solution processing. Nano Energy 1(2):221-246

33. Warwick MEA, Binions R (2014) Advances in thermochromic vanadium dioxide films. J Mater Chem A 2(10):3275-3292

34. Li Y, Ji S, Gao Y et al (2013) Core-shell $\mathrm{VO}_{2} @ \mathrm{TiO}_{2}$ nanorods that combine thermochromic and photocatalytic properties for application as energy-saving smart coatings. Sci Rep 3:1370

35. Sun G, Cao X, Zhou H et al (2017) A novel multifunctional thermochromic structure with skin comfort design for smart window application. Sol Energy Mater Sol Cells 159:553-559

36. Sun G, Cao X, Li X et al (2017) Low-temperature deposition of $\mathrm{VO}_{2}$ films with high crystalline degree by embedding multilayered structure. Solar Energy Mater Solar Cells 161:70-76

37. Sun G, Zhou H, Cao X et al (2016) Self-assembled multilayer structure and enhanced thermochromic performance of spinodally decomposed $\mathrm{TiO}_{2}-\mathrm{VO}_{2}$ thin film. ACS Appl Mater Interfaces 8(11):7054-7059

38. Li S, Li Y, Qian K et al (2014) Functional fiber mats with tunable diffuse reflectance composed of electrospun $\mathrm{VO}_{2} / \mathrm{PVP}$ composite fibers. ACS Appl Mater Interfaces 6(1):9-13

39. Li Y, Ji S, Gao Y et al (2013) Core-regenerated vapor-solid growth of hierarchical stem-like $\mathrm{VO}_{x}$ nanocrystals on $\mathrm{VO}_{2} @$ $\mathrm{TiO}_{2}$ core-shell nanorods: microstructure and mechanism. Cryst Eng Commun 15(41):8330-8336

40. Li S, Li Y, Jiang M et al (2013) Preparation and characterization of self-supporting thermochromic films composed of $\mathrm{VO}_{2}(\mathrm{M}) @ \mathrm{SiO}_{2}$ nanofibers. ACS Appl Mater Interfaces 5(14):6453-6457

41. Li Y, Ji S, Gao Y et al (2013) Modification of Mott phase transition characteristics in $\mathrm{VO}_{2} @ \mathrm{TiO}_{2}$ core/shell nanostructures by misfit-strained heteroepitaxy. ACS Appl Mater Interfaces 5(14):6603-6614

42. Li R, Ji S, Li Y et al (2013) Synthesis and characterization of plate-like $\mathrm{VO}_{2}(\mathrm{M}) @ \mathrm{SiO}_{2}$ nanoparticles and their application to smart window. Mater Lett 110:241-244
43. Chen Y, Zeng X, Zhu J et al (2017) High performance and enhanced durability of thermochromic films using $\mathrm{VO}_{2} @ \mathrm{ZnO}$ core-shell nanoparticles. ACS Appl Mater Interfaces 9(33):27784-27791

44. Ke Y, Wen X, Zhao D et al (2017) Controllable fabrication of two-dimensional patterned $\mathrm{VO}_{2}$ nanoparticle, nanodome, and nanonet arrays with tunable temperature-dependent localized surface plasmon resonance. ACS Nano 11(7):7542-7551

45. Zhu J, Huang A, Ma $\mathrm{H}$ et al (2017) Hybrid films of $\mathrm{VO}_{2}$ nanoparticles and a nickel(II)-based ligand exchange thermochromic system: excellent optical performance with a temperature responsive colour change. New J Chem 41(2):830-835

46. Li Y, Jiang P, Xiang W et al (2016) A novel inorganic precipitation-peptization method for $\mathrm{VO}_{2}$ sol and $\mathrm{VO}_{2}$ nanoparticles preparation: synthesis, characterization and mechanism. J Colloid Interface Sci 462:42-47

47. Wan J, Ren Q, Wu N et al (2016) Density functional theory study of M-doped ( $\mathrm{M}=\mathrm{B}, \mathrm{C}, \mathrm{N}, \mathrm{Mg}, \mathrm{Al}) \mathrm{VO}_{2}$ nanoparticles for thermochromic energy-saving foils. $\mathrm{J}$ Alloys Compd 662:621-627

48. Li M, Wu H, Zhong L et al (2016) Active and dynamic infrared switching of $\mathrm{VO}_{2}(\mathrm{M})$ nanoparticle film on ITO glass. J Mater Chem C 4(8):1579-1583

49. Lan S, Cheng C, Huang $C$ et al (2015) Synthesis of sub-10 nm $\mathrm{VO}_{2}$ nanoparticles films with plasma-treated glass slides by aqueous sol-gel method. Appl Surf Sci 357:2069-2076

50. Liu H, Wan D, Ishaq A et al (2016) Sputtering deposition of sandwich-structured $\mathrm{V}_{2} \mathrm{O}_{5} /$ Metal $(\mathrm{V}, \mathrm{W}) / \mathrm{V}_{2} \mathrm{O}_{5}$ multilayers for the preparation of high-performance thermally sensitive $\mathrm{VO}_{2}$ thin films with selectivity of $\mathrm{VO}_{2}(\mathrm{~B})$ and $\mathrm{VO}_{2}(\mathrm{M})$ polymorph. ACS Appl Mater Interfaces 8(12):7884-7890

51. Mlyuka NR, Niklasson GA, Granqvist CG (2009) Thermochromic $\mathrm{VO}_{2}$-based multilayer films with enhanced luminous transmittance and solar modulation. Phys Status Solidi a Appl Mater Sci 206(9):2155-2160

52. Mlyuka NR, Niklasson GA, Granqvist CG (2009) Thermochromic multilayer films of $\mathrm{VO}_{2}$ and $\mathrm{TiO}_{2}$ with enhanced transmittance. Solar Energy Mater Solar Cells 93(9):1685-1687

53. Morrison VR, Chatelain RP, Tiwari KL et al (2014) A photoinduced metal-like phase of monoclinic $\mathrm{VO}_{2}$ revealed by ultrafast electron diffraction. Science 346(6208):445-448

54. Ji Y, Li S, Niklasson GA et al (2014) Durability of thermochromic $\mathrm{VO}_{2}$ thin films under heating and humidity: effect of Al oxide top coatings. Thin Solid Films 562:568-573

55. Zhu J, Zhou Y, Wang B et al (2015) Vanadium dioxide nanoparticle-based thermochromic smart coating: high luminous transmittance, excellent solar regulation efficiency, and near room temperature phase transition. ACS Appl Mater Interfaces 7(50):27796-27803

56. Lv W, Huang D, Chen Y et al (2014) Synthesis and characterization of $\mathrm{Mo}-\mathrm{W}$ Co-doped $\mathrm{VO}_{2}(\mathrm{R})$ nano-powders by the microwave-assisted hydrothermal method. Ceram Int 40(8):12661-12668

57. Piccirillo C, Binions R, Parkin IP (2007) Nb-doped $\mathrm{VO}_{2}$ thin films prepared by aerosol-assisted chemical vapour deposition. Eur J Inorg Chem 2007(25):4050-4055

58. Burkhardt W, Christmann T, Meyer BK et al (1999) W- and F-doped $\mathrm{VO}_{2}$ films studied by photoelectron spectrometry. Thin Solid Films 345(2):229-235

59. Li SY, Niklasson GA, Granqvist CG (2012) Thermochromic fenestration with $\mathrm{VO}_{2}$-based materials: three challenges and how they can be met. Thin Solid Films 520(10):3823-3828

60. Li M, Magdassi S, Gao Y et al (2017) Hydrothermal synthesis of $\mathrm{VO}_{2}$ polymorphs: advantages, challenges and prospects for the application of energy efficient smart windows. Small 13(36): 1701147 
61. Jin P, Xu G, Tazawa M et al (2003) Design, formation and characterization of a novel mutifunctional window with $\mathrm{VO}_{2}$ and $\mathrm{TiO}_{2}$ coatings. Appl Phys A Mater Sci Process 77(3-4):455-459

62. Zhu BQ, Tao HZ, Zhao XJ (2016) Effect of buffer layer on thermochromic performances of $\mathrm{VO}_{2}$ films fabricated by magnetron sputtering. Infrared Phys Technol 75:22-25

63. Panagopoulou M, Gagaoudakis E, Boukos N et al (2016) Thermochromic performance of $\mathrm{Mg}$-doped $\mathrm{VO}_{2}$ thin films on functional substrates for glazing applications. Sol Energy Mater Sol Cells 157:1004-1010

64. Long S, Zhou H, Bao S et al (2016) Thermochromic multilayer films of $\mathrm{WO}_{3} / \mathrm{VO}_{2} / \mathrm{WO}_{3}$ sandwich structure with enhanced luminous transmittance and durability. RSC Adv 6(108):106435-106442

65. Sun GY, Cao X, Gao X et al (2016) Structure and enhanced thermochromic performance of low-temperature fabricated $\mathrm{VO}_{2} / \mathrm{V}_{2} \mathrm{O}_{3}$ thin film. Appl Phys Lett 109(14):143903:1-5

66. Powell MJ, Quesada-Cabrera R, Taylor A et al (2016) Intelligent multifunctional $\mathrm{VO}_{2} / \mathrm{SiO}_{2} / \mathrm{TiO}_{2}$ coatings for self-cleaning, energy-saving window panels. Chem Mater 28(5):1369-1376

67. Zhou Y, Cai Y, Hu X et al (2015) $\mathrm{VO}_{2}$ /hydrogel hybrid nanothermochromic material with ultra-high solar modulation and luminous transmission. J Mater Chem A 3(3):1121-1126

68. Zhu J, Huang A, Ma $\mathrm{H}$ et al (2016) Composite film of vanadium dioxide nanoparticles and ionic liquid-nickel-chlorine complexes with excellent visible thermochromic performance. ACS Appl Mater Interfaces 8(43):29742-29748

69. Li D, Shan Y, Huang F et al (2014) Sol-gel preparation and characterization of $\mathrm{SiO}_{2}$ coated $\mathrm{VO}_{2}$ films with enhanced transmittance and high thermochromic performance. Appl Surf Sci 317:160-166

70. Lee M, Cho J (2000) Better thermochromic glazing of windows with anti-reflection coating. Thin Solid Films 365(1):5-6

71. Lee M (2002) Thermochromic glazing of windows with better luminous solar transmittance. Solar Energy Mater Solar Cells 71(4):537-540

72. Zhang J, Wang J, Yang $\mathrm{C}$ et al (2017) Mesoporous $\mathrm{SiO}_{2} / \mathrm{VO}_{2}$ double-layer thermochromic coating with improved visible transmittance for smart window. Sol Energy Mater Sol Cells 162:134-141

73. Jin $\mathrm{P}, \mathrm{Xu} \mathrm{G}$, Tazawa $\mathrm{M}$ et al (2002) $\mathrm{A} \mathrm{VO}_{2}$-based multifunctional window with highly improved luminous transmittance. Jpn J Appl Phys 41(Part 2, No. 3A):L278-L280

74. Xu G, Jin P, Tazawa M et al (2004) Optimization of antireflection coating for $\mathrm{VO}_{2}$-based energy efficient window. Solar Energy Mater Solar Cells 83(1):29-37

75. Zhu B, Tao H, Zhao X (2016) Effect of buffer layer on thermochromic performances of $\mathrm{VO}_{2}$ films fabricated by magnetron sputtering. Infrared Phys Technol 75:22-25

76. Panagopoulou M, Gagaoudakis E, Aperathitis E et al (2015) The effect of buffer layer on the thermochromic properties of undoped radio frequency sputtered $\mathrm{VO}_{2}$ thin films. Thin Solid Films 594:310-315

77. Koo H, Xu L, Ko KE et al (2013) Effect of oxide buffer layer on the thermochromic properties of $\mathrm{VO}_{2}$ thin films. J Mater Eng Perform 22(12):3967-3973

78. Koo H, You H, Ko KE et al (2013) Thermochromic properties of $\mathrm{VO}_{2}$ thin film on $\mathrm{SiN}_{x}$ buffered glass substrate. Appl Surf Sci 277:237-241

79. Du J, Gao Y, Luo H et al (2011) Formation and metal-to-insulator transition properties of $\mathrm{VO}_{2}-\mathrm{ZrV}_{2} \mathrm{O}_{7}$ composite films by polymer-assisted deposition. Solar Energy Mater Solar Cells 95(7):1604-1609

80. Li SY, Niklasson GA, Granqvist CG (2010) Nanothermochromics: calculations for $\mathrm{VO}_{2}$ nanoparticles in dielectric hosts show much improved luminous transmittance and solar energy transmittance modulation. J Appl Phys 108(6):063525

81. Chen Z, Cao C, Chen S et al (2014) Crystallised mesoporous $\mathrm{TiO}_{2}(\mathrm{~A})-\mathrm{VO}_{2}(\mathrm{M} / \mathrm{R})$ nanocomposite films with self-cleaning and excellent thermochromic properties. J Mater Chem A 2(30):11874

82. Li W, Ji S, Qian K et al (2015) Preparation and characterization of $\mathrm{VO}_{2}-\mathrm{BaSO}_{4}$ composite films with enhanced optical properties in thermochromic field. Ceram Int 41(3):5049-5056

83. Zhou Y, Cai Y, Hu X et al (2014) Temperature-responsive hydrogel with ultra-large solar modulation and high luminous transmission for "smart window" applications. J Mater Chem A 2(33):13550-13555

84. Zhu J, Huang A, Ma H et al (2016) Solar-thermochromism of a hybrid film of $\mathrm{VO}_{2}$ nanoparticles and $\mathrm{Co}^{\mathrm{II}}$ - $\mathrm{Br}-\mathrm{TMP}$ complexes. RSC Adv 6(71):67396-67399

85. Wang X, Cao Y, Yang C et al (2016) Vanadium dioxide film protected with an atomic-layer-deposited $\mathrm{Al}_{2} \mathrm{O}_{3}$ thin film. $\mathrm{J}$ Vac Sci Technol A Vac Surf Films 34(1):01A106

86. Saitzek S, Guinneton F, Sauques L et al (2007) Thermochromic $\mathrm{CeO}_{2}-\mathrm{VO}_{2}$ bilayers: role of ceria coating in optical switching properties. Opt Mater 30(3):407-415

87. Saitzek S, Guirleo G, Guinneton F et al (2004) New thermochromic bilayers for optical or electronic switching systems. Thin Solid Films 449(1-2):166-172

88. Pan GT, Yang YL, Chong SH et al (2017) The durability study of thermochromic vanadium dioxide films with the addition of barrier coatings. Vacuum 145:158-168

89. Fahlteich J, Fahland M, Schönberger W et al (2009) Permeation barrier properties of thin oxide films on flexible polymer substrates. Thin Solid Films 517(10):3075-3080

90. Zhan Y, Xiao X, Lu Y et al (2018) Enhanced thermal stability and thermochromic properties of $\mathrm{VO}_{x}$-based thin films by roomtemperature magnetron sputtering. Solar Energy Mater Solar Cells 174:102-111

91. Lu XM, Xiao XD, Cao ZY et al (2016) A novel method to modify the color of $\mathrm{VO}_{2}$-based thermochromic smart films by solution-processed $\mathrm{VO}_{2} @ \mathrm{SiO}_{2} @ \mathrm{Au}$ core-shell nanoparticles. RSC Adv 6(53):47249-47257

92. Yin H, Yu K, Song C et al (2014) Low-temperature CVD synthesis of patterned core-shell $\mathrm{VO}_{2} @ \mathrm{ZnO}$ nanotetrapods and enhanced temperature-dependent field-emission properties. Nanoscale 6(20):11820-11827

93. Zhang Y, Fan M, Wu W et al (2012) A novel route to fabricate belt-like $\mathrm{VO}_{2}(\mathrm{M}) @ \mathrm{C}$ core-shell structured composite and its phase transition properties. Mater Lett 71:127-130

94. Huang A, Zhou Y, Li Y et al (2013) Preparation of $\mathrm{V}_{x} \mathrm{~W}_{1-\mathrm{x}} \mathrm{O}_{2}(\mathrm{M}) @ \mathrm{SiO}_{2}$ ultrathin nanostructures with high optical performance and optimization for smart windows by etching. J Mater Chem A 1(40):12545-12552

95. Zhou Y, Ji S, Li Y et al (2014) Microemulsion-based synthesis of $\mathrm{V}_{1-x} \mathrm{~W}_{x} \mathrm{O}_{2} @ \mathrm{SiO}_{2}$ core-shell structures for smart window applications. J Mater Chem C 2(19):3812-3819

96. Dong X, Fang X, Lv M et al (2015) Improvement of the humidity stability of organic-inorganic perovskite solar cells using ultrathin $\mathrm{Al}_{2} \mathrm{O}_{3}$ layers prepared by atomic layer deposition. J Mater Chem A 3(10):5360-5367

97. Tong K, Li R, Zhu J et al (2017) Preparation of $\mathrm{VO}_{2} / \mathrm{Al}-\mathrm{O}$ coreshell structure with enhanced weathering resistance for smart window. Ceram Int 43(5):4055-4061

98. Qian X, Wang N, Li Y et al (2014) Bioinspired multifunctional vanadium dioxide: improved thermochromism and hydrophobicity. Langmuir 30(35):10766-10771

99. Zhou H, Li J, Bao S et al (2016) Use of $\mathrm{ZnO}$ as antireflective, protective, antibacterial, and biocompatible multifunction nanolayer of thermochromic $\mathrm{VO}_{2}$ nanofilm for intelligent windows. Appl Surf Sci 363:532-542 
100. Maurya D, Sardarinejad A, Alameh K (2014) Recent developments in R.F. Magnetron sputtered thin films for $\mathrm{pH}$ sensing applications-an overview. Coatings 4(4):756-771

101. Ye H, Long LS, Zhang HT et al (2013) The demonstration and simulation of the application performance of the vanadium dioxide single glazing. Sol Energy Mater Sol Cells 117:168-173

102. Long LS, Ye H, Zhang HT et al (2015) Performance demonstration and simulation of thermochromic double glazing in building applications. Sol Energy 120:55-64
103. Long LS, Ye H, Gao YF et al (2014) Performance demonstration and evaluation of the synergetic application of vanadium dioxide glazing and phase change material in passive buildings. Appl Energy 136:89-97

104. Ye H, Long LS, Zhang HT et al (2014) The energy saving index and the performance evaluation of thermochromic windows in passive buildings. Renew Energy 66:215-221 